\title{
Evaluation of the activated carbon coated with multiwalled carbon nanotubes in removal of ciprofloxacin from aqueous solutions
}

\author{
Narges Sharifpour ${ }^{1} \cdot$ Fazel Mohammadi Moghaddam ${ }^{2} \cdot$ Goshtasb Mardani $^{2} \cdot$ Mohammad Malakootian $^{1,3}(\mathbb{C}$
}

Received: 18 April 2020 / Accepted: 6 May 2020 / Published online: 19 May 2020

(C) The Author(s) 2020

\begin{abstract}
Ciprofloxacin (CIP) is a commonly used antibiotic which is excreted in significant quantities and may likely be found in environments, especially wastewater. Thus, in the present study, we aimed to remove CIP from aqueous solutions using activated carbon supported with multivalent carbon nanotubes MWCNTs/AC. Herein, we prepared the MWCNTs/AC and the structural characterization of the adsorbent was performed using the BET, FTIR, and SEM methods. In order to obtain the optimal conditions of MWCNTs/AC activity, different experimental conditions including the $\mathrm{pH}$, adsorbent dosage, contact time, initial CIP concentration, and temperature were examined. Afterward, to approach reality, the experiments were carried out under the optimal conditions using a sewage sample previously determined in terms of the BOD, COD, pH, EC, turbidity, and concentration of ciprofloxacin. Finally, the CIP levels were measured by HPLC. According to the results, the $\mathrm{pH}$ of 7 , contact time of $30 \mathrm{~min}$, adsorbent dosage of $20 \mathrm{mg} / \mathrm{L}$, temperature of $40{ }^{\circ} \mathrm{C}$, and initial CIP concentration of $20 \mathrm{mg} / \mathrm{L}$ were found to be the optimal conditions for MWCNTs/AC activity. In these conditions, the maximum removal efficiency of CIP from the synthetic and actual samples was $100 \%$ and $73 \%$, respectively. Moreover, the adsorption behavior was in compliance with the pseudo-second-order, Freundlich isotherm kinetics. According to our findings, using MWCNTs/AC led to a considerable removal of CIP from the sewage samples. Thus, the use of this adsorbent is highly recommended in order to remove other antibiotics from water and wastewater.
\end{abstract}

Keywords Ciprofloxacin $\cdot$ Multiwalled carbon nanotube $\cdot$ Activated carbon $\cdot$ Adsorption $\cdot$ Sewage

\section{Introduction}

Antibiotics are partially metabolized in the body, and 30-90\% of them remain active after excretion (Malakootian et al. 2019c). These compounds are found in different scales of nano- to micrograms per liter in various drinking water, groundwater, surface water, sewage, and wastewater sources (Javid et al. 2019). It has been shown that pharmaceutical compounds may be introduced to aquatic environments

Mohammad Malakootian

m.malakootian@yahoo.com; m_malakootian@kmu.ac.ir

1 Environmental Health Engineering Research Center, Kerman University of Medical Sciences, Kerman, Iran

2 Department of Environmental Health, School of Public Health, Shahrekord University of Medical Sciences, Shahrekord, Iran

3 Department of Environmental Health, School of Public Health, Kerman University of Medical Sciences, Kerman, Iran through the pharmaceutical industry and hospital disposal and also by humans and animals excretions (Javid et al. 2019). The presence of antibiotics in the environment, even at low concentrations, could impose serious threats to humans and also can result in high antibiotic resistance in long term (Malakootian et al. 2019a; Nasiri et al. 2019). In this regard, ciprofloxacin (CIP) is a broad-spectrum antibiotic of the fluoroquinolones group used in treatment of different infections (Bajpai et al. 2014). CIP was initially found to be useful against legionella and typhoid diseases and then is widely prescribed and used against different gram-negative and gram-positive bacteria (Bajpai et al. 2014).

Previously, various methods of chemical oxidation processes (Mahdizadeh and Malakootian 2019), membrane filtrations (Malakootian et al. 2019b), biological treatments (Malakootian et al. 2018a), and ozonation techniques (Malakootian et al. 2018b) have been investigated to remove different compounds from aqueous media, including antibiotics. Among the above-mentioned approaches, adsorption process is regarded as an efficient alternative, due to its 
wide adaptability, simplicity of design, convenience, and ease of operation, especially when the adsorbent is relatively cost-effective and easy to access. However, developing the adsorbents with easy preparation, high efficiency, and low cost is still a challenge and problem in the application of antibiotic adsorption. And among adsorbents, activated carbon (AC) is applied widely, due to having large surface area, high adsorption capacity, and versatile selectivity (Loqman et al. 2017). Although the use of AC to adsorb and remove antibiotics from aqueous environments has been investigated so far (Al-Othman et al. 2012; El-Shafey et al. 2012; $\mathrm{Li}$ et al. 2015), their separation after treatment remains the main defect of such powdered AC or nanosize adsorbents, which may result in the generation of secondary pollution.

Recently, multiwalled carbon nanotubes (MWCNTs) have been introduced as novel adsorbents which are shown to be useful in different types of waste treatments (Parlayici et al. 2015). High porosity, multilayered, cost affectivity, biocompatibility, and capacity of MWCNTs make them ideal adsorbents to remove various toxic compounds from aqueous solutions (Iijima 1991; Upadhyayula et al. 2009). Thus, modified AC and MWCNTs can improve their adsorptive properties as well as separation after treatment. On the other hand, the adsorption of drugs by biodegradable and natural polymers is considered as one of the new methods for antibiotic removal. Polysaccharides-based adsorbents are particularly used to treat Pharmaceutical Industry Wastewater because of their easy availability and high removal capacities for a broad range of antibiotics (Rasoulzadeh et al. 2019). Moreover, in order to improve the extraction properties of the polysaccharides-based adsorbents have been used extensively as adsorbents to produce the polysaccharide matrix and a synergistic effect of an inorganic filler (Massoudinejad et al. 2019; Malakootian et al. 2018c).

Different types of modified AC adsorbents or multiwall carbon nanotubes have been used previously to adsorb toxic metals or pharmaceutics from wastewaters. In this regard, Liu et al. (2019) showed that hexadecyl trimethyl ammonium bromide modified AC was a powerful adsorbent to remove the sulfamethazine and sulfamethoxazole antibiotics from aqueous solutions. Shah et al. (2019) used nanozerovalent manganese-catalyzed $\mathrm{S}_{2} \mathrm{O}_{8}{ }^{2-}$ to degrade CIP. Their results showed that nanozerovalent manganese was highly efficient and resulted in degradation of CIP; however, the addition of $\mathrm{S}_{2} \mathrm{O}_{8}{ }^{2-}$ improved its removal efficiency. Xu et al. conducted a study to eliminate antibiotics from wastewater using CNT/LaVO4 nanostructures. According to their results, optimized CNT/LaVO4 nanostructures resulted in efficient photodegradation of antibiotics. Their findings showed that CNT/LaVO4 nanostructures led to tetracycline removal twice higher than the pure LaVO4 (Xu et al. 2019). Malakootian et al. (2015) investigated the efficiency of oxidized multiwall carbon nanotubes to remove $\mathrm{pb}^{2}+$ from aquatic solutions. Their results revealed that oxidized multiwall carbon nanotubes had a high capacity to remove $\mathrm{Pb}^{2+}$ from aqueous solutions.

Thus, considering the advantages of carbon nanotubes as well as modified AC adsorbents (such as enhanced adsorption capacity and easy separation of AC after treatment), in the present study, we aimed to prepare $\mathrm{AC}$-supported multiwalled carbon nanotubes (MWCNTs/AC) to remove CIP from an aquatic solution.

\section{Materials and methods}

\section{Chemicals and study principals}

All experiments of this study were carried out between January 2018 and July 2018 at the Environmental Health Engineering Laboratory of the Shahrekord University of Medical Sciences and the Environmental Health Engineering Research Center of the Kerman University of Medical Sciences. Multiwall carbon nanotubes used in this study were purchased from the Research Institute of Iran Petroleum Industry. CIP, with $99 \%$ purity, was provided from the Temad Company (Temad, Garmdareh, Tehran, Iran). Other chemicals and solutions including granular AC, sulfuric acid, chloride acid, potassium permanganate, sodium hydroxide, and ethanol were obtained from Merck (Darmstadt, Germany).

Sampling is done instantly, and according to the following formulas:

$V=Q / £ Q \times V$

where $V$ is sample volume taken at any turn (in), $Q$ is effluent rate at sampling time (in), $V$ is sample volume required (in), and $Q £$ is total wastewater rate in period of $24 \mathrm{~h}$.

\section{Preparing functionalized MWCNTs}

As described in detail elsewhere (Parlayici et al. 2015), to prepare the adsorbent, initially, the MWCNTs, prior to their functionalization, were dispersed in a sufficient amount of $95 \%$ ethanol at $25^{\circ} \mathrm{C}$ for $1 \mathrm{~h}$ in a sonication bath in order to increase the surface area. Then, using filtration membranes, the nanoparticles were separated from slurry, washed with certain amount of distilled water, and subsequently dried at $100{ }^{\circ} \mathrm{C}$ under vacuum conditions. Afterward, $100 \mathrm{mg}$ of MWCNTs was dispersed in $200 \mathrm{ml}$ of $0.5 \mathrm{M}$ sulfuric acid and sonicated for a further $30 \mathrm{~min}$. Moreover, $250 \mathrm{mg}$ of $\mathrm{KMnO}_{4}$ was dissolved in a $0.5 \mathrm{M}$ sulfuric acid solution with a volume of $200 \mathrm{ml}$ and added to the abovementioned MWCNTs $/ \mathrm{H}_{2} \mathrm{SO}_{4}$ solution. Afterward, the obtained MWC$\mathrm{NTs} / \mathrm{KMnO}_{4}$ mixture was heated and refluxed at $150{ }^{\circ} \mathrm{C}$ for 
$5 \mathrm{~h}$. At the final stage, temperature was reduced to $25^{\circ} \mathrm{C}$ and $10 \mathrm{ml}$ of the concentrated HCL was added to the target solution. The mixture was finally filtered and washed again with distilled water, and subsequently, the obtained functionalized MWCNTs were dried at $100{ }^{\circ} \mathrm{C}$ under vacuum conditions. The experimental design work used in this study is presented in detail in Fig. 1.

\section{Preparation of MWCNTs/AC}

To prepare AC coated with multiwalled carbon nanotubes (MWCNTs/AC), $100 \mathrm{mg}$ of AC and $100 \mathrm{mg}$ of the functionalized multiwall carbon nanotubes were separately dispersed in $100 \mathrm{ml}$ of the ethanol solution for $10 \mathrm{~min}$ in a sonication bath. Then, both the solutions were mixed and kept in an oven under $80{ }^{\circ} \mathrm{C}$ for about $16 \mathrm{~h}$ until dry. Afterward, the MWCNTs/AC was obtained and placed in a desiccator for next experiments.

\section{Assessment of the CIP adsorption using MWCNTs/AC}

Herein, we aimed to find the optimum conditions, in which the highest adsorption of CIP occurred by MWCNTs/AC. Initially, we prepared a stock solution of CIP with a concentration of $1000 \mathrm{mg} / \mathrm{L}$ which was used to obtain different synthetic solutions with the desired concentration of CIP. In the later step, different parameters including $\mathrm{pH}(3,5,7,9$, and 12), adsorbent dosage (5, 10, 15, 20, 25, and $30 \mathrm{mg} / \mathrm{L})$, contact time $(10,20,30,40,50$, and $60 \mathrm{~min})$, initial CIP concentration $(20,40,60,80$, and $100 \mathrm{mg} / \mathrm{L})$, and temperature $\left(10,20,30,40\right.$, and $\left.50^{\circ} \mathrm{C}\right)$ were examined to obtain the optimal conditions of the adsorbent activity. In this regard, different synthetic solutions with certain concentrations of CIP were adjusted to a specific $\mathrm{pH}$, mixed with a certain amount of adsorbent, and shaken for a definite contact time. It needs to be mentioned that $\mathrm{pH}$ was adjusted using both the $0.1 \mathrm{M} \mathrm{HCl}$ and $0.1 \mathrm{M} \mathrm{NaOH}$ solutions. Moreover, the concentration of CIP was determined using Waters 1200 Alliance HPLC equipped with a reverse used with a wavelength of $277 \mathrm{~nm}$ with column C18 (5 mm, $4.6 \mathrm{~mm}$ id. $250 \mathrm{~mm}$, KNAUER, AZURA, Germany) and a moving phase of $23 \%$ acetonitrile and $77 \%$ water with injection flow rate of $1 \mathrm{ml} /$ min (Mifsud et al. 2014).

The removal efficiency and adsorption capacity of the adsorbent for CIP were calculated using Eqs. 2 and 3, respectively.

$R(\%)=\frac{C_{i}-C_{e}}{C_{i}} \times 100$

where $C_{i}$ is the initial concentration of CIP and $C_{e}$ stands for the secondary concentration of CIP.

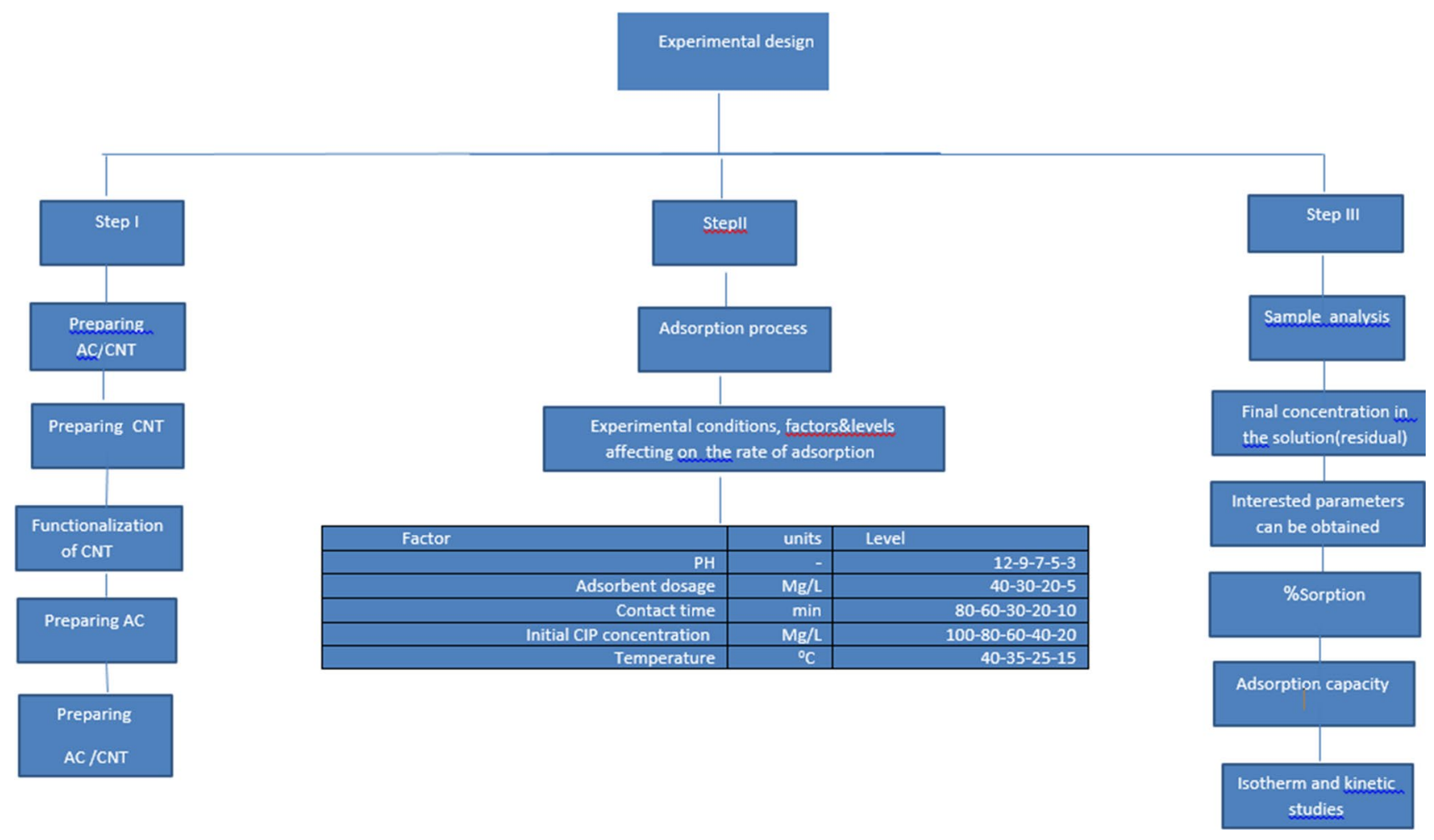

Fig. 1 Experimental design involved in this study 
$Q_{e}=\frac{\left(C_{i}-C_{e}\right) V}{M}$

where $Q_{e}$ is the adsorption capacity of the adsorbent (mg adsorption per each gram of the adsorbent) and $C_{0}$ and $C_{e}$ are the initial and equilibrium concentration of CIP $(\mathrm{mg} / \mathrm{L})$, respectively. Moreover, $V$ is the volume of the synthetic CIP solution (L) and $M$ is the weight of adsorbent (gr).

\section{The structural analysis of MWCNTs/AC}

To study the morphology of the adsorbent, scanning electron microscopy (SEM) analysis was used. The porosity and surface area of the adsorbent were measured using the BET method. Afterward, the surface chemical groups of the adsorbent were examined using the Fourier transform infrared spectroscopy (FTIR).

\section{Investigation of the MWCNTs/AC performance to remove CIP from a sewage sample under optimal conditions}

As mentioned previously, different parameters were examined to obtain the optimal conditions, in which the highest removal of CIP was obtained using MWCNTs/AC. Herein, to approach realistic conditions, we conducted other experiments using a hospital sewage which was already determined in the cases of BOD, COD, TSS, and CIP. These experiments were carried out under the previously determined optimal conditions to investigate the MWCNTs/AC performance to remove CIP from an actual sample.

\section{Adsorbent recovery/desorption}

In order to reduce the adsorption costs, the use of adsorption recovery/desorption has considerable importance in any system. In the present study, three different methods of adsorbent recovery were examined to be used in next experiments. The first method was washing the adsorbent. In this method, the adsorbent was washed three times with distilled water and then dried and reused. In the second method, the washing was performed with $1 \mathrm{M} \mathrm{H}_{2} \mathrm{SO}_{4}$, and then dried and used again. In the third method, $1 \mathrm{M} \mathrm{NaOH}$ was used as the washing buffer to regenerate the adsorbent.

\section{Results and discussion}

\section{The structural analysis of the MWCNTs/AC adsorbent}

As mentioned, the structural characteristic of the MWCNTs/ AC adsorbent was analyzed using three different methods of SEM, BET, and FITR. The morphological properties of MWCNTs/AC were studied by SEM analysis. The result of SEM analysis is illustrated in Fig. 2. According to these findings, it is obvious that multiwalled carbon nanotubes are attached to the surface of AC sheets. Moreover, the agglomeration of MWCNTs is detectable on AC.
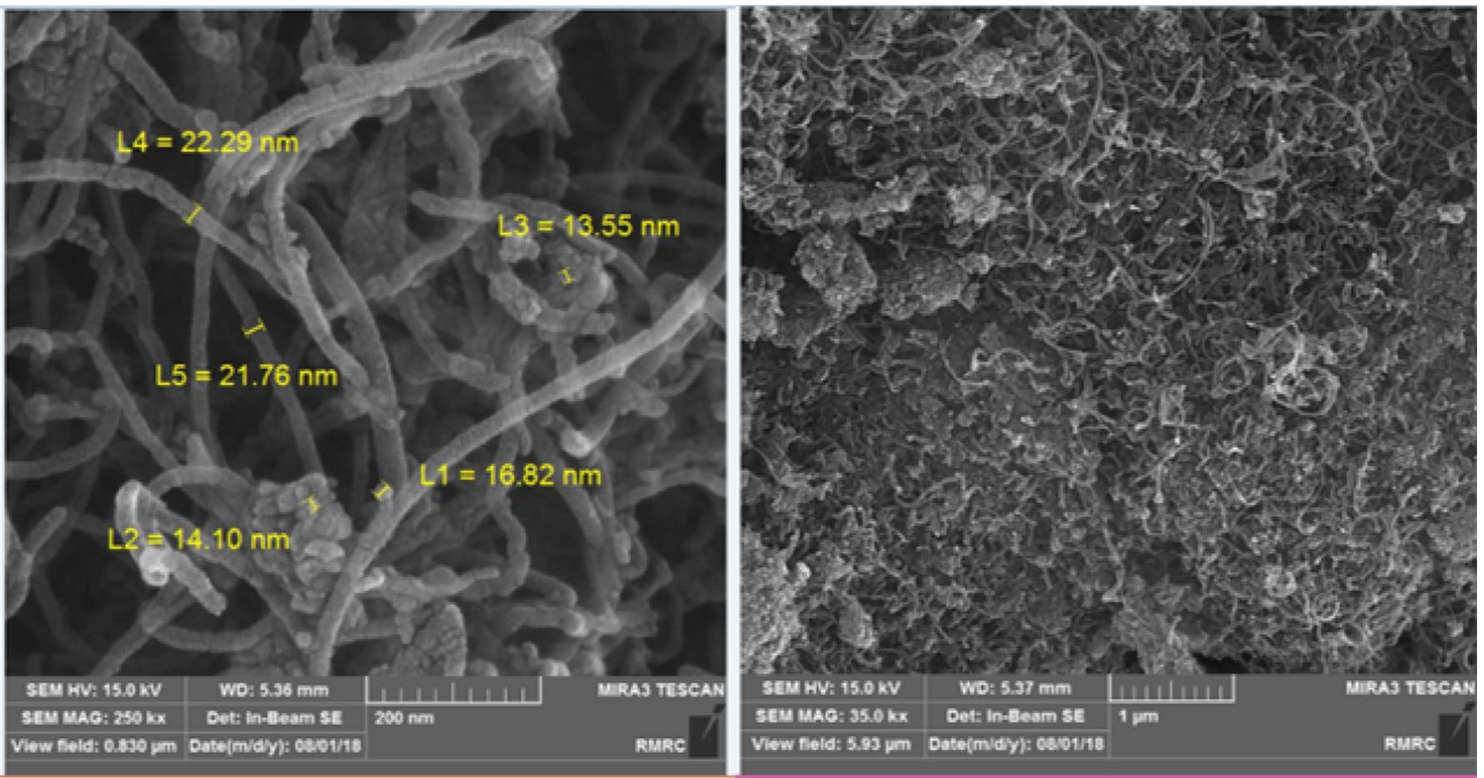

Fig. 2 The SEM analysis of MWCNTs/AC. Two pictures with different magnifications are presented 
The data of the surface area and porosity of the MWCNTs/AC adsorbent were provided by BET analysis. The subsequent results are summarized in Table 1.

Moreover, we performed FTIR analysis in order to characterize the chemical bonds and surface functional groups of the MWCNTs/AC adsorbent. The FTIR was performed in the spectrum of the $500-4000 \mathrm{~cm}^{-1}$ wave number range, and the results are illustrated in Fig. 3.

According to Fig. $3 \mathrm{a}$, the peak at the $500-4000 \mathrm{~cm}^{-1}$ wave number range is attributed to the stretching vibration of the $\mathrm{O}-\mathrm{H}$ bond. However, the peak at $1642 \mathrm{~cm}^{-1}$ is attributed to the bending vibration of the same band. Moreover, the bands of 2307.52, 1744.49 , and $676.4 \mathrm{~cm}^{-1}$ are attributed to the $\mathrm{C}-\mathrm{H}, \mathrm{C}=\mathrm{C}$, and $\mathrm{C}=\mathrm{O}$ stretchings, respectively, in carbon nanotubes. In Fig. 3B, 3432.91 and $1633.74 \mathrm{~cm}^{-1}$ represent the stretching and bending vibration of the $\mathrm{O}-\mathrm{H}$ band of $\mathrm{H}_{2} \mathrm{O}$, which were adsorbed by $\mathrm{AC}$, respectively. Moreover, the peak at $12,923.85 \mathrm{~cm}^{-1}$ is attributed to the $\mathrm{C}-\mathrm{H}$ band of AC. The peak at $586.38 \mathrm{~cm}^{-1}$ in Fig. $3 \mathrm{C}$ is attributed to the band between $\mathrm{KMnO}_{4}$ and others, while the peaks at 1744.49 and $1166.4 \mathrm{~cm}^{-1}$ represent $\mathrm{C}=\mathrm{C}$ (the alkene group) and $\mathrm{C}-\mathrm{H}$ vibration stretchings of carbon nanotubes, respectively.

Table 1 The surface area and porosity of MWCNTs/AC adsorbent obtained by BET analysis

\begin{tabular}{ll}
\hline Surface area & $7.0816 \times 10^{2} \mathrm{~m}^{2} / \mathrm{g}$ \\
Porosity volume & $0.5306 \mathrm{~cm}^{3} / \mathrm{g}$ \\
Average diameter of pores & $2.9970 \mathrm{~nm}$ \\
\hline
\end{tabular}

Finally, in Fig. 3d, the peaks of 2922.39 and $1720.53 \mathrm{~cm}^{-1}$ are attributed to the $\mathrm{C}-\mathrm{H}$ band and $\mathrm{C}=\mathrm{C}$ stretching of $\mathrm{AC}$, respectively. However, $462.60 \mathrm{~cm}^{-1}$ is related to the $\mathrm{Mn}-\mathrm{O}$ band in $\mathrm{MnO}_{4}$ (Luo et al. 2013).

According to the results obtained by the FTIR, the peak at $462.60 \mathrm{~cm}^{-1}$ attributed to the $\mathrm{Mn}-\mathrm{O}$ stretching confirmed the presence of the functional $\mathrm{KMnO}_{4}$ group. Moreover, Fig. $3 \mathrm{~d}$ shows that the frequency of the $\mathrm{C}-\mathrm{H}, \mathrm{C}-\mathrm{C}$, and $\mathrm{CO}-\mathrm{H}$ groups tended to shift to lower wavelengths which were due to the presence of manganese and carbon functional groups (Basahel et al. 2009; Wepasnick et al. 2011; Luo et al. 2013). Altogether, these results confirmed the presence of functional groups in MWCNTs/AC.

According to the MWCNTs/AC spectrum in Fig. 4 (line b), the CNT after batch mode sorption shows the presence of new peaks at 800 and $1246.61 \mathrm{~cm}^{-1}$, as well as a little shift to almost all the aforementioned peaks. Comparative evaluation of the two spectrum shows that some of these peaks were shifted or disappeared, and new peaks were detected. The shifts can be due to the decrease in force constant of $\mathrm{O}-\mathrm{H}$ bond because of the hydrogen bonding between absorbed ciprofloxacin and CNT. The changes observed in the spectra showed the possible involvement of the functional groups on the surface of the MWCNTs/AC in sorption process.

In the next steps, the impacts of different parameters including concentration of the adsorbent, initial concentration of CIP, contact time, and the solution $\mathrm{pH}$ were
Fig. 3 FTIR analysis of a AC, $\mathbf{b}$ carbon nanotubes, $\mathbf{c}$ functionalized nanotubes with $\mathrm{KMnO}_{4}$, and $\mathbf{d} \mathrm{AC}$ coated with multiwalled carbon nanotubes (MWCNTs/AC)

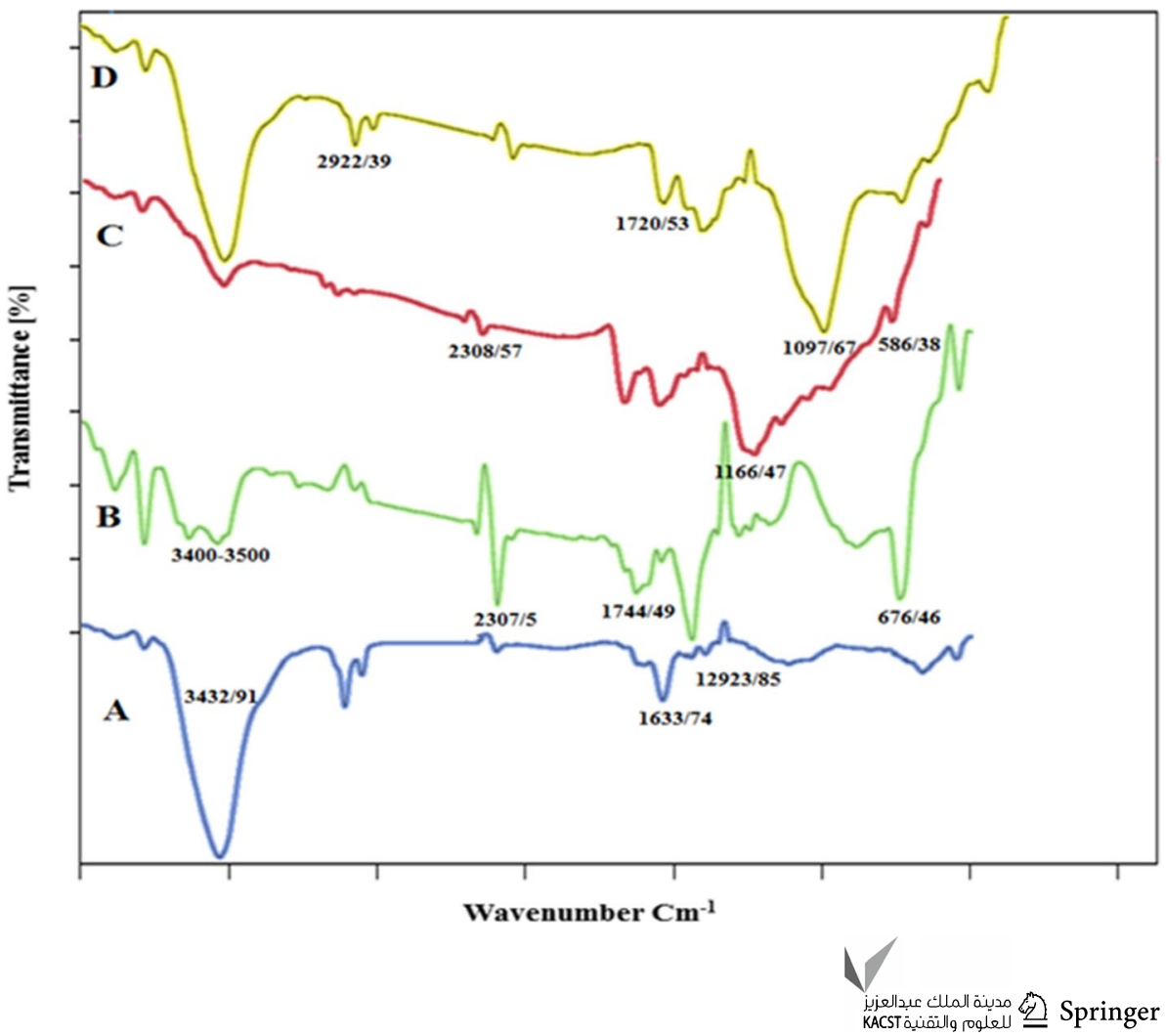


Fig. 4 FTIR spectrum of CNT before (a) and after (b) the ciprofloxacin adsorption

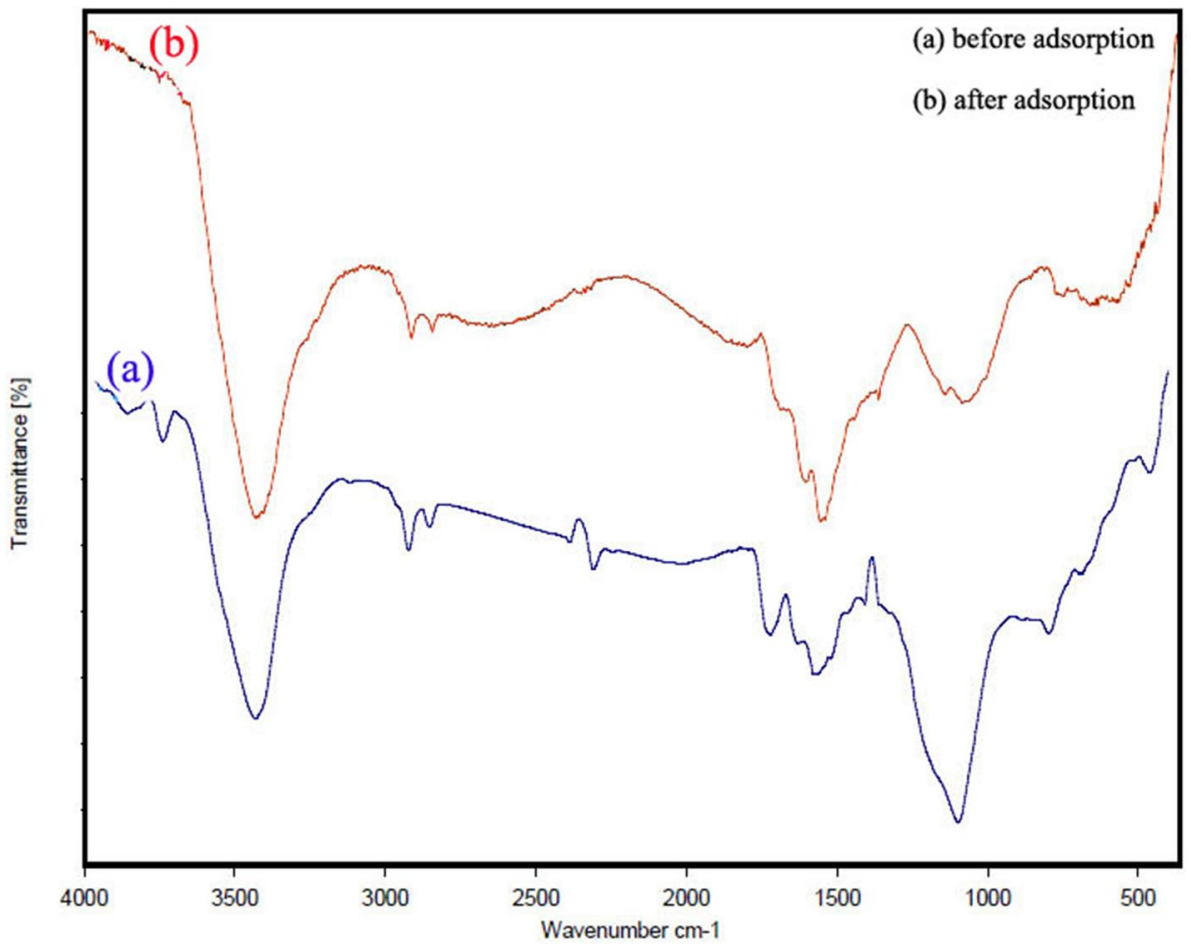

examined, which may contribute to the removal of CIP by MWCNTs/AC.

\section{The effect of the solution pH on removal efficiency}

To investigate the effect of the solution $\mathrm{pH}$ on the MWCNTs/ AC performance, different $\mathrm{pH}$ values of 3, 5, 7, 9, and 12 were considered. To this end, different solution $\mathrm{pH}$ values were examined under the constant condition, i.e., the contact time of $30 \mathrm{~min}$, adsorbent of $20 \mathrm{mg} / \mathrm{L}$, initial CIP concentration of $20 \mathrm{mg} / \mathrm{L}$, and temperature of $40{ }^{\circ} \mathrm{C}$.

According to the results, the CIP removal efficiency by the MWCNTs/AC adsorbent was promoted by enhancing the $\mathrm{pH}$ value from 3 to 7 , which reached the maximum level (100\%) at $\mathrm{pH}$ 7. The removal efficiency also decreased slowly with increasing $\mathrm{pH}$ from 8 to 12 . The results are presented in Fig. 5.

The capacity of the MWCNTs/AC adsorbent to remove CIP was also studied regarding different concentrations of this antibiotic. In this regard, we examined the removal efficiency of CIP considering different initial concentrations of $20,40,60,80$, and $100 \mathrm{mg} / \mathrm{ml}$. These experiments were performed in different $\mathrm{pH}$ values of 3,7 , and 12 ; however, the other conditions remained constant (the contact time of $30 \mathrm{~min}$, adsorbent of $20 \mathrm{mg}$, and temperature of $40^{\circ} \mathrm{C}$ ). As shown in Fig. 6, our findings suggested that by increasing
Fig. 5 The effect of the different $\mathrm{pH}$ values on the removal efficiency of CIP by MWCNTs/ AC. (Conditions: adsorbent dosage of $20 \mathrm{mg} / \mathrm{L}$, temperature of $40{ }^{\circ} \mathrm{C}$, initial CIP concentration of $20 \mathrm{mg} / \mathrm{L}$, and contact time of $30 \mathrm{~min}$ )

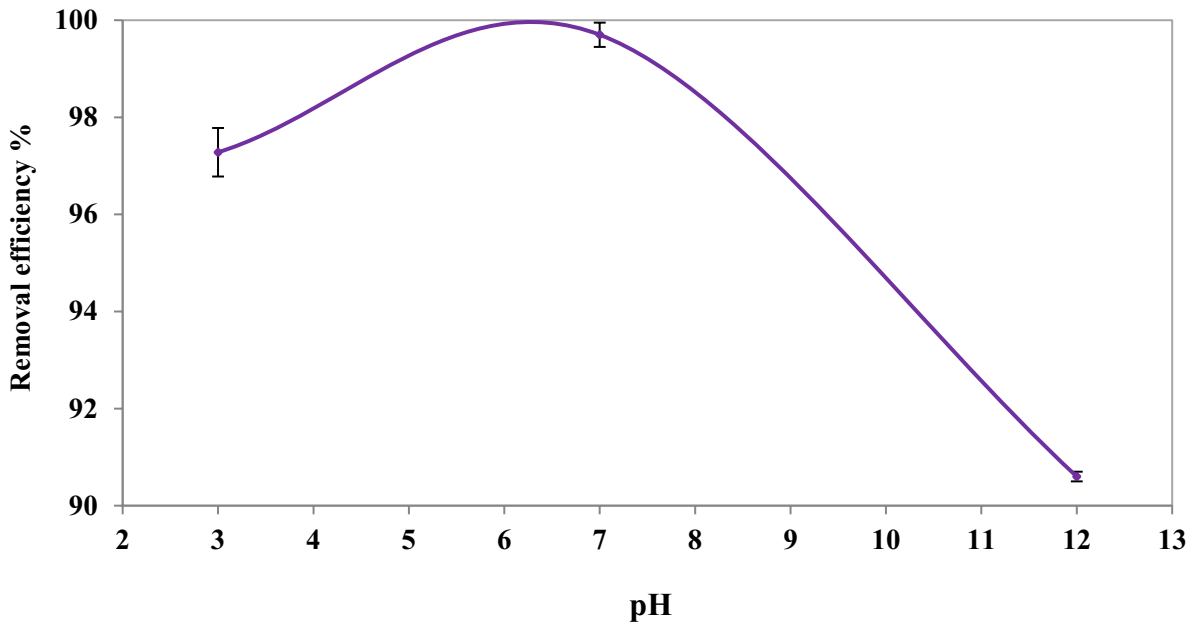


Fig. 6 The effect of the initial ciprofloxacin concentration of adsorption at different $\mathrm{pH}$ values of 3, 7, and 12. (Conditions: adsorbent dosage of $20 \mathrm{mg} / \mathrm{L}$, temperature of $40^{\circ} \mathrm{C}, \mathrm{pH} 7$, and contact time of $30 \mathrm{~min}$ )

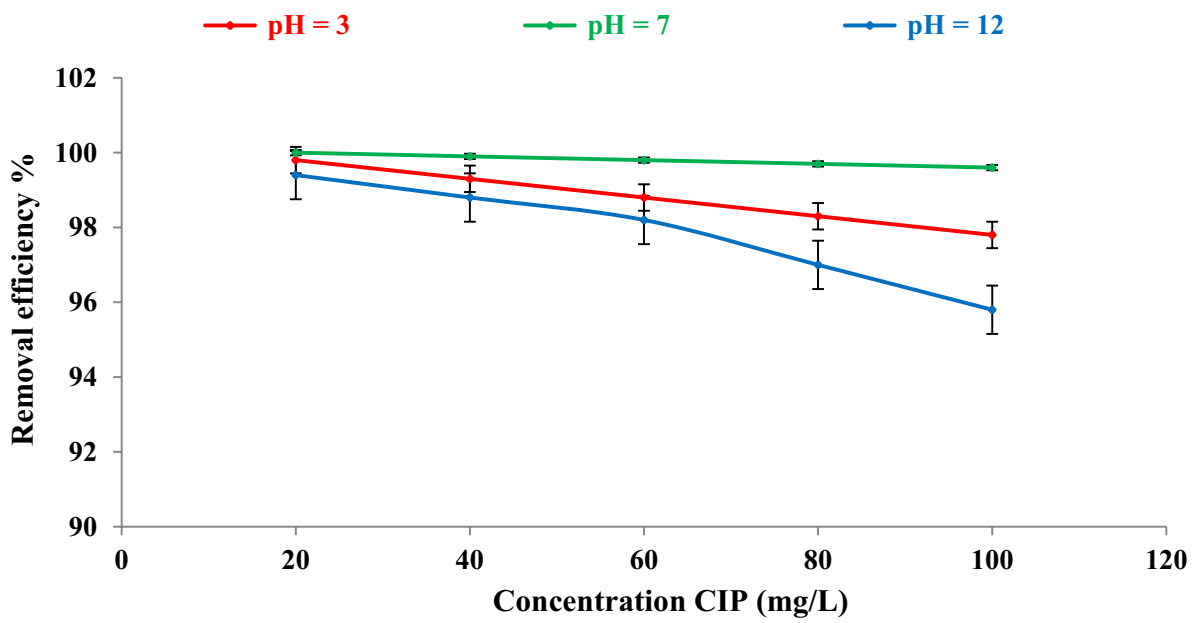

the initial concentration of CIP, the subsequent removal efficiency decreased at the $\mathrm{pH}$ values of 3,7 , and 12 . However, according to Fig. 6, this decrease was more obvious in higher $\mathrm{pH}$ values.

\section{The effect of contact time on the removal efficiency of CIP}

In this stage, we aimed to find the potential effects of contact time on the CIP adsorption by MWCNTs/AC. Thus, we conducted different experiments in time points of 10, 20, 30, 40, 50, and $60 \mathrm{~min}$. Moreover, according to the previous findings, the initial concentration of CIP was set up at $20 \mathrm{mg} / \mathrm{L}$ and the experiments were performed with $20 \mathrm{mg}$ of the adsorbent at $40{ }^{\circ} \mathrm{C}$ and at different $\mathrm{pH}$ values of 3,7 , and 12 (Fig. 7).

As shown in Fig. 7, by increasing the contact time, the adsorption increased in different $\mathrm{pH}$ values; however, the patterns were not similar. In $\mathrm{pH} 7$, the adsorption increased by increasing the contact time to $30 \mathrm{~min}$, while it reached the equilibrium by increasing time from 30 to $60 \mathrm{~min}$. However, in the case of $\mathrm{pH} 12$, the adsorption continuously increased with an increase in contact time.

\section{The effect of the MWCNTs/AC dosage on the removal efficiency of CIP}

As a fact, the concentration of any adsorbent can potentially affect its removal efficiency. In the present study, we examined different concentrations of MWCNTs/AC $(5,20$, 30 , and $40 \mathrm{mg} / \mathrm{L}$ ), to find the optimum dosage in which the highest adsorption of CIP occurred. The experiments were carried out at the initial concentration of $20 \mathrm{mg} / \mathrm{L} \mathrm{CIP}$, contact time of $30 \mathrm{~min}$, and temperature of $40{ }^{\circ} \mathrm{C}$ under different pH conditions of 3, 7, and 12 (Fig. 8).

According to obtained results (Fig. 8), by increasing the adsorbent concentration from 5 to $20 \mathrm{mg} / \mathrm{L}$ the adsorption of CIP increased, but the removal efficiency somehow remained unchanged by increasing from 20 to $30 \mathrm{mg} / \mathrm{L}$. Moreover, the adsorption pattern was relatively similar in different $\mathrm{pH}$ conditions.
Fig. 7 The effect of contact time on the adsorption of CIP by MWCNTs/AC at different $\mathrm{pH}$ values of 3,7 , and 12 . (Conditions: adsorbent dosage of $20 \mathrm{mg} / \mathrm{L}$, temperature of $40{ }^{\circ} \mathrm{C}$, initial CIP concentration of $20 \mathrm{mg} / \mathrm{L}$, and $\mathrm{pH} 7$ )

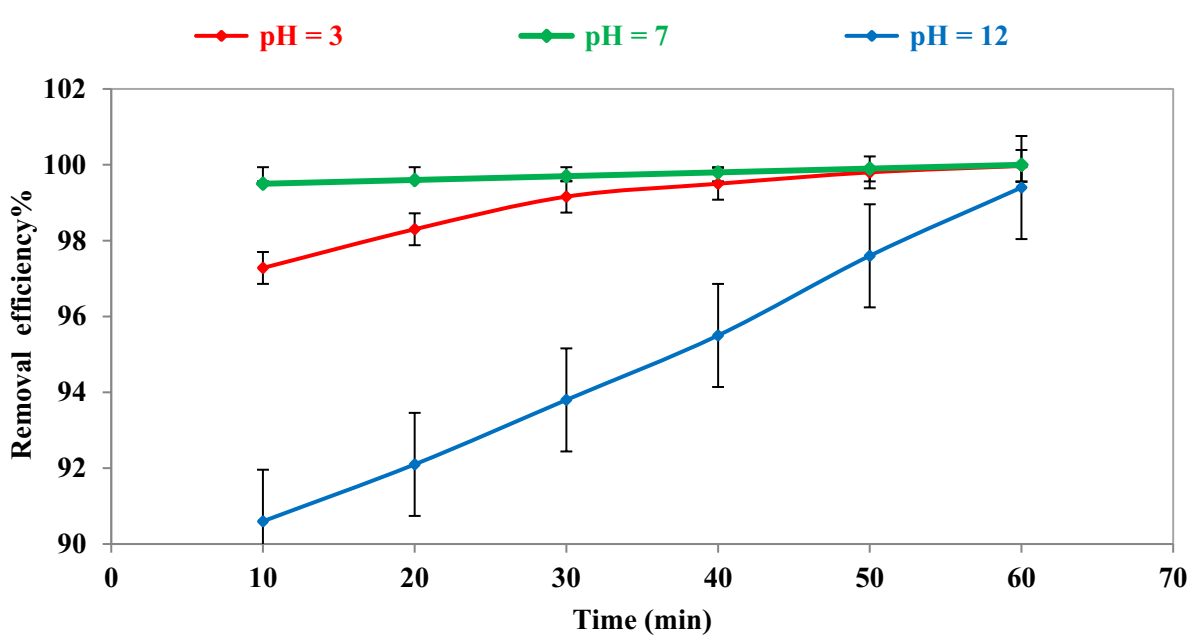


Fig. 8 The effect of adsorbent dosage on the efficacy of CIP removal at $\mathrm{pH}$ values of 3,7 , and 12. (Conditions: $\mathrm{pH} 7$, temperature of $40{ }^{\circ} \mathrm{C}$, initial CIP concentration of $20 \mathrm{mg} / \mathrm{L}$, and contact time of $30 \mathrm{~min}$ )

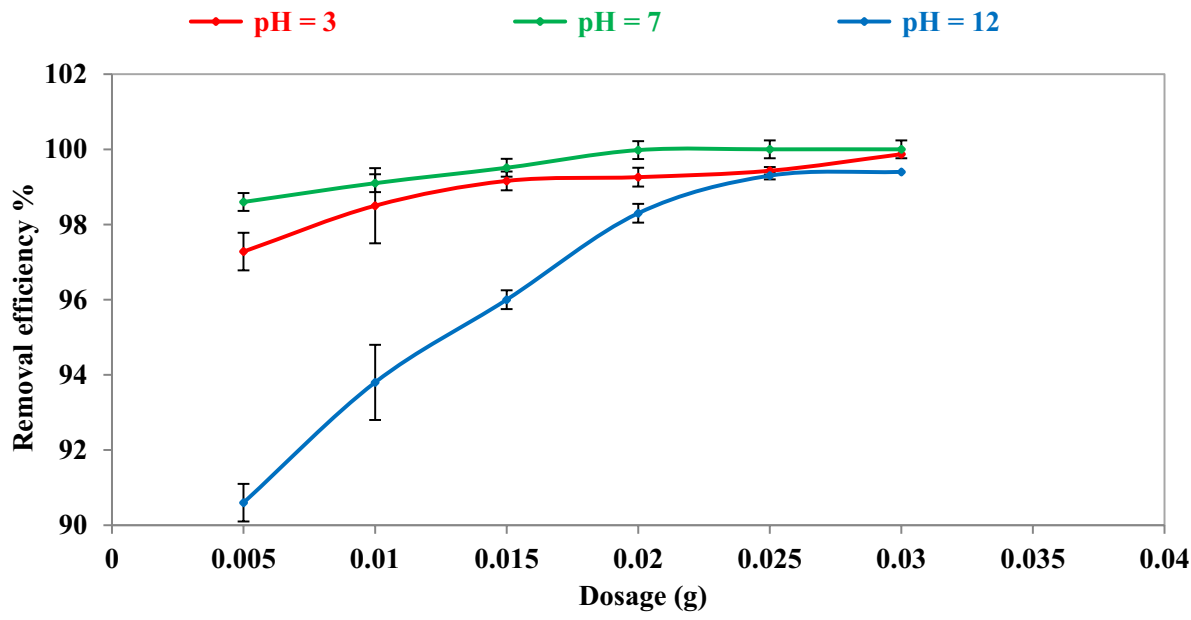

\section{The effect of temperature on the removal efficiency of CIP}

In the present study, the effect of different temperatures $\left(10,20,30,40\right.$, and $\left.50{ }^{\circ} \mathrm{C}\right)$ on the adsorption of CIP by the MWCNTs/AC adsorbent was investigated. The experiments were performed at the adsorbent concentration of $20 \mathrm{mg} / \mathrm{L}$, contact time of $30 \mathrm{~min}$, and the initial CIP concentration of $20 \mathrm{mg} / \mathrm{L}$. According to Fig. 9, the removal efficiency of CIP increased with increasing the temperature. Similar pattern was observed in different $\mathrm{pH}$ conditions.

\section{Determination of adsorption kinetics}

To determine the kinetics of adsorption, the previous information obtained from the effect of adsorbent dosage at $40{ }^{\circ} \mathrm{C}$ and different time intervals under $\mathrm{pH}$ values of 3,7 , and 12 was used (Fig. 10).

In this regard, intraparticle diffusion (IPD), the pseudo-firstorder (PFO), and pseudo-second-order (PSO) models were used to investigate the mechanism of adsorption, by which
MWCNTs/AC eliminated CIP. The kinetic models are presented in the following linear formulas:

$\log q_{e}-q_{t}=\log q_{e}-\frac{k_{1}}{2.303} t$

$\frac{t}{q_{t}}=\frac{1}{k_{2} q_{e}^{2}}+\frac{1}{q_{e}} t$

where $q_{e}$ and $q_{t}$ are the amounts of pollutant adsorbed on an absorbent $(\mathrm{mg} / \mathrm{g})$ at equilibrium and time $t(\mathrm{~min})$, respectively. $k_{1}$ is the rate constant of PFO (1/min). Values of $k_{1}$ and $q_{e}$ can be obtained by the slope and intercepts of the plot of $\log \left(q_{e}-q_{t}\right)$ versus $t$. In Eq. 6, $k_{2}$ is the rate constant of PSO (g/mg min).

In addition, the intraparticle diffusion model (IPD) is conveniently used to describe the diffusion mechanism. The model can be epitomized as follows (Alimohammadi et al. 2017; Balarak et al. 2017):

$q_{t}=k_{\mathrm{id}} \cdot t^{1.2}+C$
Fig. 9 The effect temperature on CIP adsorption by MWC$\mathrm{NTs} / \mathrm{AC}$ at $\mathrm{pH}$ values of 3,7 , and 12. (Conditions: adsorbent dosage of $20 \mathrm{mg} / \mathrm{L}, \mathrm{pH} 7$, initial CIP concentration of $20 \mathrm{mg} / \mathrm{L}$, and contact time of $30 \mathrm{~min}$ )

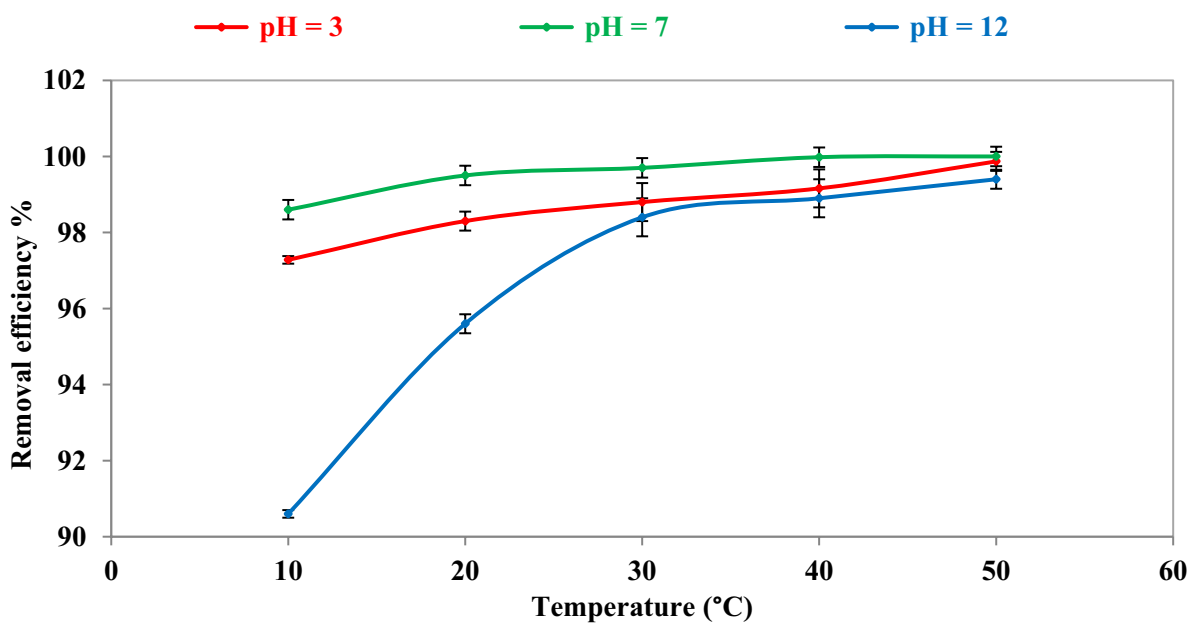


Fig. 10 The adsorption kinetics. a First-order kinetics related to the adsorption of CIP by MWCNTs/AC at $\mathrm{pH} \mathrm{3,} \mathrm{7,} \mathrm{and}$ 12 ; $\mathbf{b}$ the pseudo-second-order model of CIP adsorption by MWCNTs/AC at $\mathrm{pH} 3,7$, and 12 ; and $\mathbf{c}$ the intraparticle diffusion model of CIP adsorption by MWCNTs/AC at pH 3, 7 , and 12
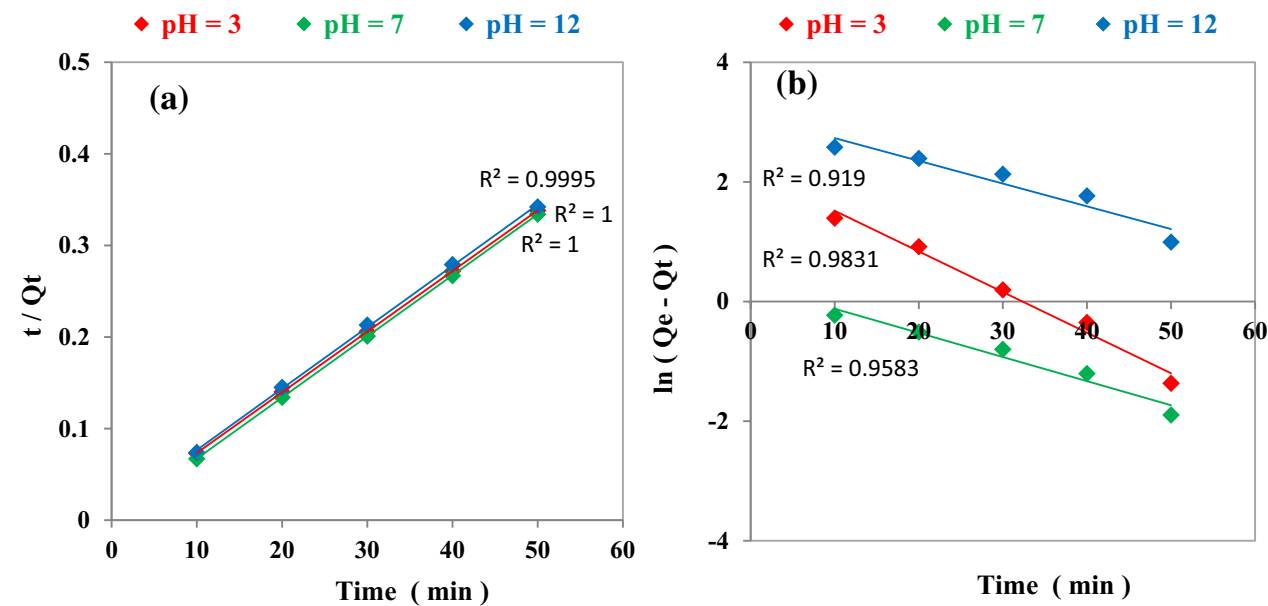

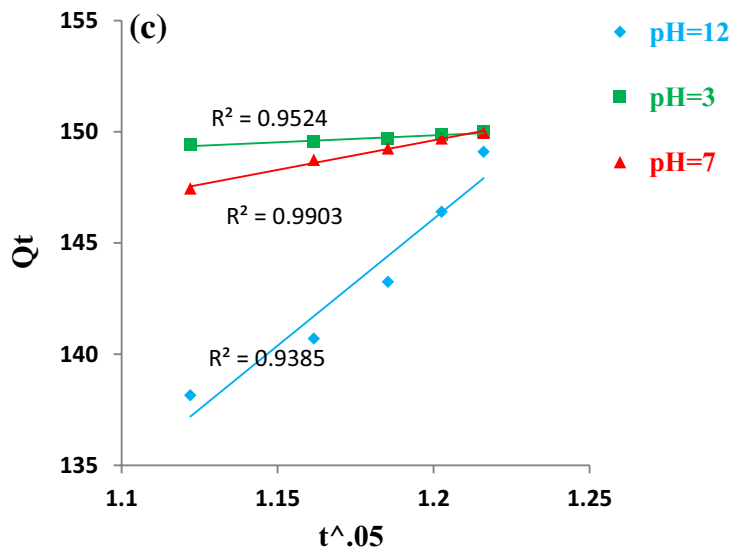

where $k_{\mathrm{id}}$ is the rate constant for intraparticle diffusion (mg/g). $C$ is the intercept and represents the thickness of the boundary layer $(\mathrm{mg} / \mathrm{g})$, the effect of which depends on the intercept value.

As a matter of fact, in the pseudo-second-order, it was assumed that two reactions occurred. One of the reactions proceeded more rapidly, and the subsequent reaction proceeded at a lower rate and continued for a long period of time (Arasteh et al. 2010; Dehghani et al. 2014). The kinetic adsorption parameters of the first-order and pseudo-secondorder models are given in Table 2.

According to the results, the mechanism of adsorption followed the pseudo-second-order model. As shown in Table 2, the equilibrium adsorption capacity $q_{e}(\mathrm{Cal})$ values are close up to the experimental $q_{e}$ (Exp) values, indicating the applicability of this kinetic model for the adsorption process behavior. Also, $R_{L}$ values show the high rate of the initial adsorption. Based on the intraparticle diffusion model, the high $C$ parameter values showed that the effect of the boundary layer was also responsible for adsorption. The multilinearity of the plot of $q$ versus $t^{0.5}$ and/or deviation of the plots from the origin further confirms that the process of adsorption is complex and some other mechanisms along with intraparticle diffusion control the steps of the process (Jerold et al. 2017).

\section{Determination of adsorption isotherms}

In this study, the Langmuir, Freundlich, and Temkin isotherm models were used to interpret and describe the data obtained from the adsorption of CIP.

The Langmuir isotherm model shows that distribution of solute molecules onto the surface of adsorbent has a monolayer pattern. As a solute molecule attaches to the active site placed on the adsorbent, no further adsorption can occur at that site (Naushad et al. 2013). The linear form of Langmuir isotherm model is expressed via Eq. (7):

$\frac{C_{e}}{q_{e}}=\frac{1}{K_{a} q_{m}}+\frac{C_{e}}{q_{m}}$

Separation factor $\left(R_{\mathrm{L}}\right)$, as a dimensionless parameter, is presented via Eq. (8).

$R_{\mathrm{L}}=\frac{1}{1+K_{a} C_{0}}$ 
Table 2 Adsorption kinetics parameters for ciprofloxacin at $\mathrm{pH} \mathrm{3,} \mathrm{7,} \mathrm{and} 12$

\begin{tabular}{|c|c|c|c|c|}
\hline $\mathrm{pH}$ & $Q_{e}(\mathrm{mg} / \mathrm{g})$ & $Q_{\text {cal }}(\mathrm{mg} / \mathrm{g})$ & $K_{1}(1 / \mathrm{min})$ & $R^{2}$ \\
\hline \multicolumn{5}{|c|}{ Pseudo-first-order kinetics model } \\
\hline 3 & 149.955 & 8.984 & 0.0679 & 0.9831 \\
\hline 7 & 150 & 1.325 & 0.0403 & 0.9583 \\
\hline 12 & 149.100 & 22.437 & 0.0380 & 0.9190 \\
\hline $\mathrm{pH}$ & $Q_{e}(\mathrm{mg} / \mathrm{g})$ & $Q_{\text {cal }}(\mathrm{mg} / \mathrm{g})$ & $K_{2}(\mathrm{~g} / \mathrm{mg} \min )$ & $R^{2}$ \\
\hline \multicolumn{5}{|c|}{ Pseudo-second-order kinetics model } \\
\hline 3 & 14.955 & 151.057 & 0.137 & 1 \\
\hline 7 & 150 & 149.925 & 0.0890 & 1 \\
\hline 12 & 149.100 & 149.254 & 0.0047 & 0.9995 \\
\hline $\mathrm{pH}$ & $Q_{e}(\mathrm{mg} / \mathrm{g})$ & $K_{\mathrm{id}}\left(\mathrm{mg} / \mathrm{g} \cdot \min ^{1 / 2}\right)$ & $C(\mathrm{mg} / \mathrm{g})$ & $R^{2}$ \\
\hline \multicolumn{5}{|c|}{ Intraparticle diffusion model } \\
\hline 3 & 149.955 & 6.23 & 142.35 & 0.9524 \\
\hline 7 & 150 & 26.59 & 117.7 & 0.9903 \\
\hline 12 & 149.100 & 114.03 & 9.24 & 0.9385 \\
\hline
\end{tabular}

where Langmuir constants $\left(C_{e}, q_{e}, q_{m}\right.$ and $\left.K_{a}\right)$ refer to the equilibrium concentration of CIP in a solution $\left(\mathrm{mg} \mathrm{L}^{-1}\right)$, the amount of adsorbed CIP $\left(\mathrm{mg} \mathrm{g}^{-1}\right)$, the maximum adsorption capacity of monolayer $\left(\mathrm{mg} \mathrm{L}^{-1}\right)$, and adsorption energy ( $\mathrm{L}$ $\mathrm{mg}^{-1}$ ), respectively, which were calculated using the plat of $\frac{C_{e}}{q_{e}}$ versus $C_{e}$ (Naghipour et al. 2016).

Freundlich isotherm model was used to determine the multilayer adsorption of adsorbate on the surface of adsorbent. It also assumes that adsorption occurs on heterogeneous surfaces and can be expressed using Eq. (9) (Pourkarim et al. 2017);

$\log q_{e}=\log K_{\mathrm{f}}+\frac{1}{n}\left(\log C_{e}\right)$

where Freundlich isotherm constants $\left(K_{\mathrm{f}}\right.$ and $\left.n\right)$ are the extent of adsorption $\left(\mathrm{mg} \mathrm{g}^{-1}\right)$ and adsorption intensity of system calculated from the plot of $\log q_{e}$ versus $\log C_{e}$.

The Temkin model is used to determine the adsorption heat (adsorption energy) and interactions between adsorbent and adsorbate. This isotherm assumes that the decrease in the adsorption energy of all the molecules in a layer along with the monolayer sorption on the active sites is due to the interactions between adsorbent and adsorbate. The linear form of the Temkin model is as follows (Bazrafshan et al. 2015; Massoudinejad et al.) 2019:

$q_{e}=B_{1} \ln \left(K_{t}\right)+B_{1} \ln \left(C_{e}\right)$

where $B_{1}\left(\mathrm{RT} / b_{1}\right)$ denotes the Temkin constant $(\mathrm{J} / \mathrm{mol}) . R$ is the universal gas constant and equal to $8.314 \mathrm{~J} / \mathrm{mol} \mathrm{K}$. $T$ is the absolute temperature $\left({ }^{\circ} \mathrm{K}\right)$. $k_{t}$ and $b_{1}$ represent the equilibrium binding constant $(\mathrm{L} / \mathrm{g})$ and the heat of adsorption ( $\mathrm{kJ} / \mathrm{mol})$, respectively.
The whole data related to the three models are summarized in Table 3, and the equilibrium curves at different $\mathrm{pH}$ conditions are shown in Fig. 11.

According to the results (Table 3), the maximum adsorption capacity for the Langmuir model in $\mathrm{pH}$ values of 3, 7, and 12 was obtained 181.502, 208.937, and 209.755, respectively. These findings showed great potential capacity of the adsorbent to remove CIP from wastewater. However, the results showed that the Freundlich isotherm model in different $\mathrm{pH}$ values of 3,7 , and 12 with $R^{2}=0.9966$, $R^{2}=0.9966$, and $R^{2}=0.9937$, respectively, performed better compared to the Langmuir isotherm. Moreover, due to that the $1 / \mathrm{n}$ slope ranged between 0 and 1 , it can be assumed that the amount of the adsorption was desirable. In addition, the $n>1$ amount may assume that the adsorption process occurred in a physical, simple, and fast manner (Dehghani et al. 2014). In addition, based on the data obtained, the magnitude of $b_{1}$ value showed the fast removal of CIP at the initial stage, and the smallness of $k_{t}$ value showed the weak bonding of CIP molecules onto the composite.

\section{Determination of adsorption thermodynamics}

In the present study, we also determined whether the adsorption process by MWCNTs/AC was spontaneous. The data of adsorption thermodynamics are presented in Table 4.

As shown by the results, the negative values were obtained for $\Delta G^{\circ}$, indicating that the CIP adsorption by the MWCNTs/AC adsorbent was a spontaneous process. In addition, $\Delta H^{\circ}$ values indicated that the CIP adsorption was an endothermic process. Furthermore, the negative values of $\Delta S^{\circ}$ revealed that the adsorption process of CIP on the adsorbent was associated with decreased entropy. Due to that 
Table 3 Parameters of Langmuir and Freundlich isotherm models for CIP adsorption at different $\mathrm{pH}$ of 3, 7, and 12

\begin{tabular}{|c|c|c|c|c|c|}
\hline $\mathrm{pH}$ & $Q_{m}(\mathrm{mg} / \mathrm{g})$ & & $K_{\mathrm{L}}(\mathrm{L} / \mathrm{mg})$ & $R_{\mathrm{L}}$ & $R^{2}$ \\
\hline \multicolumn{6}{|c|}{ Langmuir isotherm model } \\
\hline 3 & 181.502 & & 9.301 & 0.002 & 0.9406 \\
\hline 7 & 208.937 & & 30.780 & 0.001 & 0.9773 \\
\hline 12 & 209.755 & & 2.535 & 0.007 & 0.9798 \\
\hline $\mathrm{pH}$ & $n$ & & $1 / n$ & $K_{\mathrm{F}}((\mathrm{mg} / \mathrm{g})(\mathrm{L} / \mathrm{mg}) 1 / n)$ & $R^{2}$ \\
\hline \multicolumn{6}{|c|}{ Freundlich isotherm model } \\
\hline 3 & 2.5269 & & 0.3957 & 172.808 & 0.9966 \\
\hline 7 & 2.3362 & & 0.4280 & 372.206 & 0.9966 \\
\hline 12 & 2.2559 & & 0.4433 & 132.825 & 0.9937 \\
\hline $\mathrm{pH}$ & & $b_{1}$ & & $k_{\mathrm{t}}$ & $R^{2}$ \\
\hline \multicolumn{6}{|c|}{ Temkin isotherm model } \\
\hline 3 & & 0.0531 & & 50.08 & 0.9209 \\
\hline 7 & & 0.0474 & & 205.20 & 0.9621 \\
\hline 12 & & 0.0466 & & 1715 & 0.9767 \\
\hline
\end{tabular}

Fig. 11 Adsorption isotherms, a Langmuir isotherm related to the adsorption of CIP by MWCNTs/AC. (Conditions; pH 3, 7, and 12); b Freundlich isotherm of CIP adsorption by MWCNTs/AC. (Conditions: pH 3, 7, and 12); and c Temkin isotherm of CIP adsorption by MWCNTs/AC. (Conditions: $\mathrm{pH}$ 3,7 , and 12 )

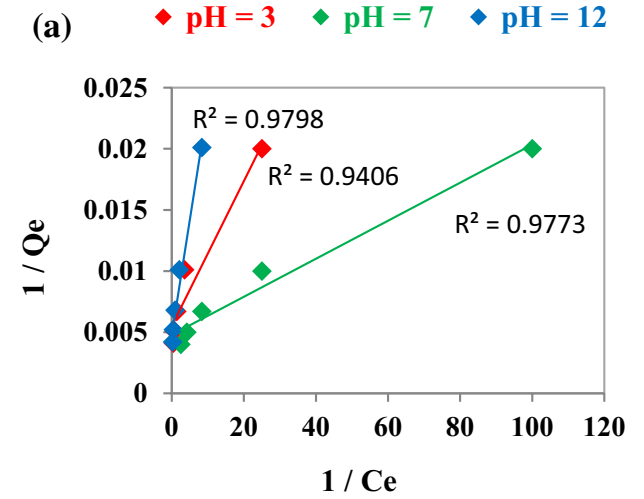

(b) $\diamond \mathrm{pH}=3 \diamond \mathrm{pH}=7 \diamond \mathrm{pH}=12$

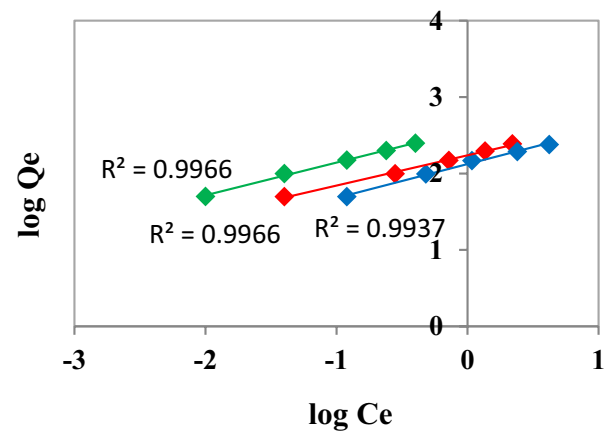

(c)
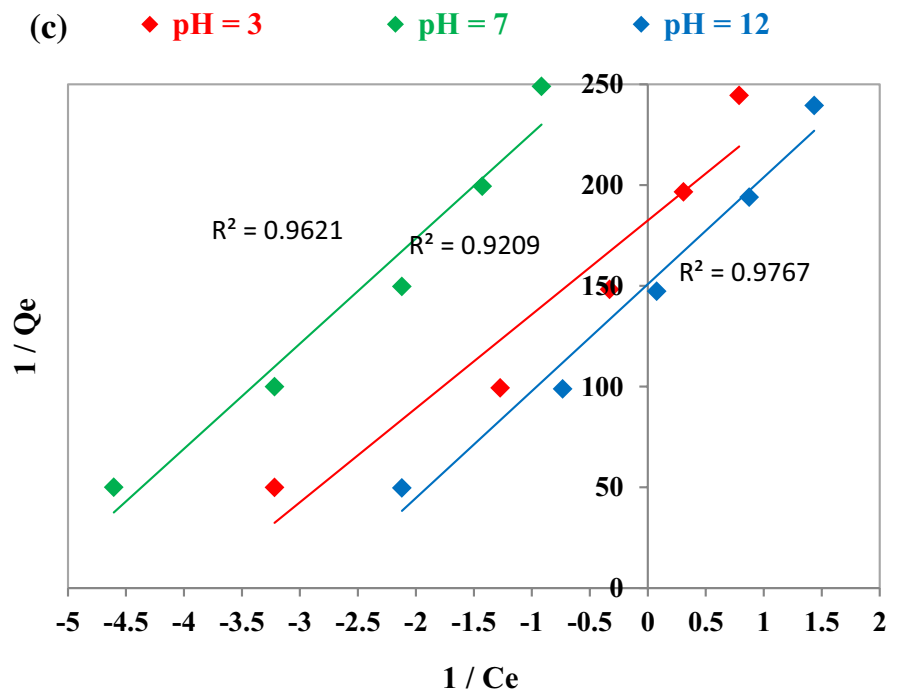
Table 4 The thermodynamic results of CIP adsorption by MWCNTs/ $\mathrm{AC}$ at $\mathrm{pH} 3,7$, and 12

\begin{tabular}{|c|c|c|c|c|c|}
\hline$T(\mathrm{~K})$ & $C_{e}(\mathrm{mg} / \mathrm{L})$ & $K_{\mathrm{P}}$ & $\begin{array}{l}\Delta G^{\circ}(\mathrm{kJ} / \\
\mathrm{mol})\end{array}$ & $\begin{array}{l}\Delta H^{\circ}(\mathrm{kJ} / \\
\mathrm{mol})\end{array}$ & $\begin{array}{l}\Delta S^{\circ}(\mathrm{J} / \\
\mathrm{mol} \mathrm{K})\end{array}$ \\
\hline \multicolumn{6}{|l|}{ pH 3} \\
\hline 283 & 145.920 & 4.493 & -10.571 & -51.306 & -216.323 \\
\hline 293 & 147.450 & 4.947 & -12.117 & & \\
\hline 303 & 148.200 & 5.327 & -13.419 & & \\
\hline 313 & 148.740 & 5.678 & -14.799 & & \\
\hline 323 & 149.805 & 7.560 & -20.302 & & \\
\hline \multicolumn{6}{|l|}{ pH 7} \\
\hline 283 & 147.900 & 5.171 & -12.167 & -86.745 & -346.863 \\
\hline 293 & 149.250 & 6.210 & -15.128 & & \\
\hline 303 & 149.550 & 6.722 & -16.934 & & \\
\hline 313 & 149.850 & 7.823 & -20.358 & & \\
\hline 323 & 150 & 10.127 & -27.195 & & \\
\hline \multicolumn{6}{|l|}{ pH 12} \\
\hline 283 & 135.900 & 3.182 & 7.487 & -54.239 & -218.727 \\
\hline 293 & 143.400 & 3.995 & 9.732 & & \\
\hline 303 & 147.600 & 5.035 & -12.684 & & \\
\hline 313 & 148.35 & 5.415 & -14.91 & & \\
\hline 323 & 149.100 & 6.026 & -16.182 & & \\
\hline
\end{tabular}

$\Delta G^{\circ}$ ranged between 0 and 20 , it can be speculated that the adsorption was a physical process ( $\mathrm{Li}$ et al. 2018). The thermodynamic results of the CIP adsorption by MWCNTs/AC in $\mathrm{pH}$ of 3, 7, and 12 are described in Table 4 and Fig. 12.

\section{The MWCNTs/AC performance to remove CIP from sewage samples in optimal conditions}

In this step, we aimed to determine the adsorption capacity of MWCNTs/AC using sewage samples obtained from the Hajar Hospital, Shahrekord, Iran. Sewage was sampled with the coordination and permission of the Hajar Hospital. In this regard, we examined the quality of the sewage samples
Table 5 Physicochemical properties of sewage sample obtained from Hajar Hospital in Shahrekord

\begin{tabular}{lll}
\hline Parameter & Amount & Dimension \\
\hline COD & 415 & $\mathrm{mg} / \mathrm{L}$ \\
BOD & 320 & $\mathrm{mg} / \mathrm{L}$ \\
$\mathrm{pH}$ & 7.1 & - \\
$\mathrm{EC}$ & 853.91 & $\mu \mathrm{s} / \mathrm{cm}$ \\
Opacity & 93 & $\mathrm{NTU}$ \\
Concentration of CIP & 1.12 & $\mathrm{mg} / \mathrm{L}$ \\
\hline
\end{tabular}

in terms of COD, BOD, pH, EC, opacity, and CIP concentration, which is summarized in Table 5.

The experiments were carried out under the optimal conditions (the contact time of $30 \mathrm{~min}$, adsorbent dosage of $20 \mathrm{mg} / \mathrm{L}$, and temperature of $40{ }^{\circ} \mathrm{C}$ ), as determined previously. The results showed that in this condition, $73 \%$ of CIP was removed by MWCNTs/AC.

\section{Adsorbent recovery}

As previously mentioned, three different washing methods were used for adsorbent recovery. According to Fig. 13, washing with $\mathrm{NaOH}$ obtained the highest value of adsorbent recovery, in which $96.7 \%$ of the initial adsorbent was recovered. However, only 94.1 and $86.5 \%$ of the initial adsorbent after treatment were recovered using distilled water and $\mathrm{H}_{2} \mathrm{SO}_{4}$, respectively.

\section{Effect of solution pH on removal efficiency}

One of the parameters that can affect the adsorption process is the $\mathrm{pH}$ of a solution. The reason is that the $\mathrm{pH}$ of a solution may change the surface chemistry of the adsorbent, as well as the charges of adsorbate residues. Thus, it can
Fig. 12 Thermodynamics of CIP adsorption by MWCNTs/ $\mathrm{AC}$ at $\mathrm{pH} 3,7$, and 12

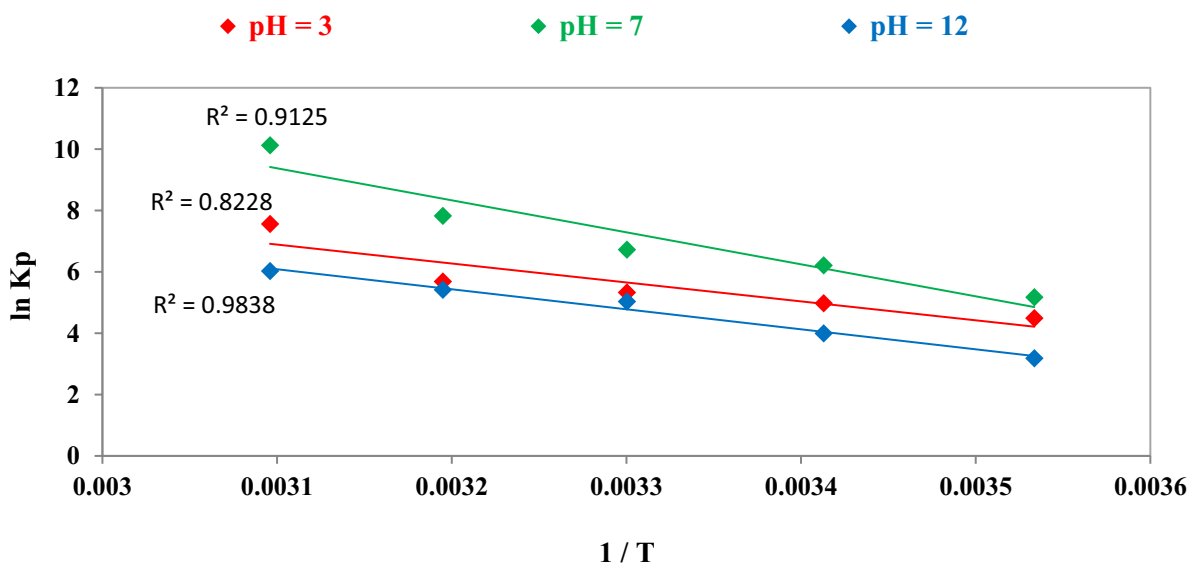




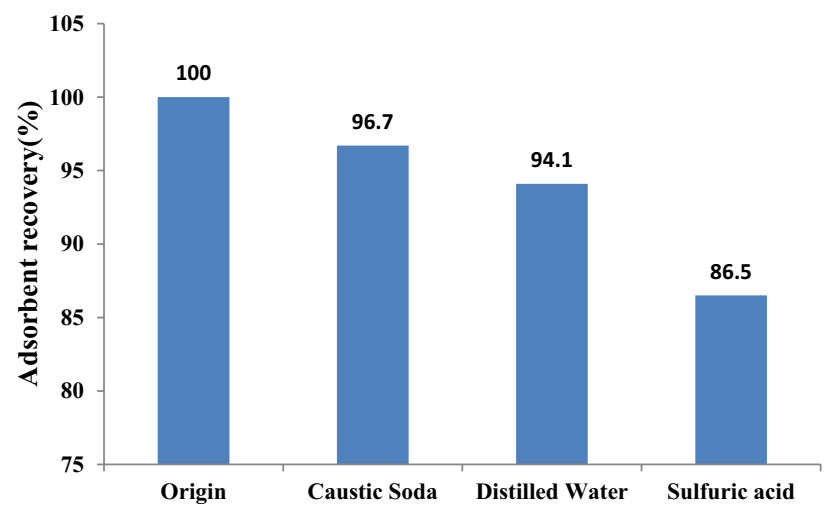

Fig. 13 The adsorbent recovery using three different washing solutions of $\mathrm{NaOH}$, distilled water, and $\mathrm{H}_{2} \mathrm{SO}_{4}$

influence the chemical interaction between the adsorbent and adsorbate (Li et al. 2009). The results showed that the CIP removal efficiency increased with increasing the $\mathrm{pH}$ value from 3 to 7 and reached its maximum level at $\mathrm{pH} 7$. However, by increasing $\mathrm{pH}$ from 8 to 12 , the CIP adsorption decreased. This may be due to that the oxygen-containing functional groups were deionized with higher rate in the alkaline $\mathrm{pH}$ region, which, in turn, led to the adsorption of $\mathrm{H}_{2} \mathrm{O}$ molecules to the surface of the adsorbent. These $\mathrm{H}_{2} \mathrm{O}$ molecules may also intervene with the adsorption of CIP molecules by MWCNTs/AC and can result in decreased removal efficiency in higher pH values (Al-Kaim et al. 2008; Bazrafshan et al. 2013; Xiao et al. 2014).

Similar to our result, Liu et al. (2019) showed that the maximum removal efficiency $(85.24 \%)$ of sulfamethazine and sulfamethoxazole from aqueous solutions was obtained at pH 5-7 by AC-modified hexadecyl trimethyl ammonium. In another study, Ibrahim et al. investigated the CIP adsorption using AC obtained from palm leaflets. They found that the peak removal efficiency of CIP was achieved at $\mathrm{pH} 6$ (El-Shafey et al. 2012).

These findings are consistent with our results and show that the highest electrostatic interactions between the adsorbent and adsorbate are in the neutral $\mathrm{pH}$ region (El-Shafey et al. 2012).

\section{Effect of the initial CIP concentration on removal efficiency}

It was observed that by increasing the initial concentration of CIP, the removal efficiency decreased, which is more likely to be due to the limited availability of the active sites for the adsorption of CIP (Ghobadi et al. 2013).

In this regard, Malakootian (2017) investigated the removal of 4-chlorophenol from aqueous environments using oxidized multiwalled carbon nanotubes and concluded that by increasing the initial concentration of 4-chlorophenol from 15 to $80 \mathrm{mg} / \mathrm{L}$, the removal efficiency decreased from 91.8 to $79 \%$ (Malakootian 2017).

Al-Heetimi et al. (2014) also investigated the adsorption of CIP hydrochloride from aqueous solutions using Iraqi Porcelinaite. They found that increasing the CIP concentration improved the removal efficiency; however, this is not true for high concentrations (Al-Heetimi et al. 2014). Their results are not consistent with the results of the present study, and those reported by Malakootian (2017) and Al-Heetimi et al. (2014), assuming that the increase in the CIP concentration and adsorption could be due to the driving force provided by the initial concentration of CIP to overcome the mass transfer resistance between the aqueous and solid phases (Al-Heetimi et al. 2014).

Abdelsalam et al. (2010) assessed the removal of 2, 3-dichlorophenol from aqueous solutions by multiwalled carbon nanotubes. They found that increasing the concentration of pollutant from $1 \times 10^{-4}$ to $8 \times 10^{-4} \mathrm{mg} / \mathrm{L}$ reduced the removal efficiency (Salam et al. 2010). To some extent, the results of their study are consistent with the results of the present study; accordingly, with increasing the concentration of adsorbate, the number of active sites on the adsorbent decreased (Ghobadi et al. 2013).

\section{The effect of contact time on removal efficiency}

We showed that the CIP adsorption by MWCNTs/AC increased continuously with an increase in contact time until reaching equilibrium. Moreover, a rapid removal of CIP was observed in the early stages of the adsorption process, which may likely be due to the highest adsorption capacity of the nanotubes at the beginning of the adsorption ( $\mathrm{Li}$ et al. 2010), as well as due to the high number of free active sites, which were limited as the process progressed (Bazrafshan et al. 2013).

Consistent with our findings, Parlayici et al. (2015) also showed that the removal of chromium (VI) using AC-supported-functionalized carbon nanotubes first increased by increasing contact time up to $50 \mathrm{~min}$ and then decreased or remained almost constant above $60 \mathrm{~min}$. In a study conducted by $\mathrm{Yu}$ et al., similar findings were also obtained. They observed that the CIP adsorption by multiwalled carbon nanotubes with different oxygen contents from aqueous solutions increased sharply in the first $10 \mathrm{~min}$ of the process, but reached equilibrium after $60 \mathrm{~min}$ (Yu et al. 2016). These results again confirmed the findings of our present study and especially supported the hypothesis that more active sites are available in the beginning of adsorption (Bazrafshan et al. 2013). 


\section{The effect of adsorbent dosage on removal efficiency}

According to the findings, by increasing adsorbent dosage, the removal efficiency of CIP increased. It is conceivable that, by increasing the adsorbent concentration, the binding sites increased and as a result greater amount of CIP was adsorbed (Worch 2012). In accordance with our results, Mosavi et al. and Samadi et al. in two independent studies used multiwalled carbon nanotubes to remove humic acid and amoxicillin from aquatic solutions, respectively. They found that by increasing the adsorbent, the removal efficiency increased (Moussavi et al. 2014; Samadi et al. 2014).

However, other studies yielded opposite findings. Yu et al. (2016) showed that with increasing the AC concentration obtained from palm leaflets, the removal efficiency of CIP was reduced. It is probable that the adsorption capacity of the adsorbent was not fully utilized at a higher adsorbent dosage in comparison with lower adsorbent dosages.

\section{The effect of temperature on the removal efficiency}

The adsorption of CIP increased with an increase in temperature. As a fact, by increasing temperature, the molecular movement increases and this can possibly increase the collision frequency between the adsorbent and adsorbate. Thus, the adsorption process can be enhanced. Moreover, temperature increase contributes to the activation energy of reaction and decreases the chemical adsorption capacity while increasing the physical adsorption capacity (Naghizadeh et al. 2011).

Al-Heetimi et al. also investigated the effect of temperature on CIP removal using Iraqi Porcelinaite. In line with the result of the present study, they found that the adsorption of CIP increased by the temperature increase (Al-Heetimi et al. 2014). Similarly, El-Shafey et al. (2012) also revealed that as temperature elevated, the CIP adsorption by a carbonaceous adsorbent produced from date palm leaflets also increased. They assumed that the temperature increase contributed to the adsorbent swollen and resulted in more free active sites for CIP.

\section{Isotherm of adsorption}

According to the results of the experiments, the adsorption isotherm of the present study fitted the Freundlich model better than the Langmuir model (Table 3). Similarly, AlHeetimi et al. showed that the sorption of CIP using Iraqi Porcelinaite followed the Freundlich model. In another study conducted by Dehghani et al., the performance of multiwall carbon nanotubes was explored for phenol removal from aqueous solutions. They showed that the equilibrium data followed a Freundlich isotherm model (Al-Heetimi et al.
2014, Dehghani et al. 2014). The consistency of these results with our findings can be due to the use of the same type of pollutant surveyed. However, other studies have used multiwalled carbon nanotubes and have found that the adsorption isotherm follows the Langmuir model (Bazrafshan et al. 2013; Parlayici et al. 2015; Li et al. 2018). It appears that these results from the different pollutants investigated in these studies compared with the abovementioned studies.

\section{Kinetics of adsorption}

Pseudo-first- and second-order kinetic models were used in the present study, and it was revealed that the adsorption data fitted well with pseudo-second-order model (Table 2). Therefore, it is obvious that the adsorption of CIP by MWCNTs/AC is a rate-limiting process. In other studies by El-Shafey et al. (2012), Yu et al. (2016), and Peng et al. (2015), multiwalled carbon nanotubes with different oxygen contents, chemically prepared carbon from date palm leaflets and ordered mesoporous carbon, and bamboo-based carbon were, respectively, used to remove CIP from aqueous solutions and similar results were obtained. The results showed that the kinetics of the adsorption process fitted the pseudo-second-order model (El-Shafey et al. 2012; Peng et al. 2015; Yu et al. 2016). To some extent, the results of the above-mentioned studies are consistent with the results of the present studies, which may be due to the similarity of the examined adsorbent and adsorbate.

\section{Adsorption thermodynamics}

Herein, we calculated the changes in enthalpy $\left(\Delta H^{\circ}\right)$ and entropy $\left(\Delta S^{\circ}\right)$ for the CIP adsorption. Considering the positive values obtained for $\Delta H^{\circ}$, it can be assumed that the adsorption was an endothermic process. Given that $\Delta G^{\circ}$ values were between 0 and $-20 \mathrm{~kJ} / \mathrm{mol}$, it can be concluded that the process had physical characteristics (Li et al. 2018). Moreover, the negative value of $\Delta G^{\circ}$ indicated that the adsorption process occurred spontaneously. Further, the negative values of $\Delta S^{\circ}$ indicated a decrease in randomness at the adsorbent-adsorbate interface during the adsorption of CIP onto MWCNTs/AC.

In this regard, El-Shafey et al. (2012) showed that the CIP adsorption by AC produced from palm leaflets was an endothermic, spontaneous process which had physical characteristics. The same findings were also obtained by Al-Heetimi et al. (2014) and Mao et al. (2016), who used an Iraqi Porcelinaite adsorbent and a modified magnetic carbon composite, respectively, for CIP removal from aquatic solutions.

Altogether, the maximum removal efficiency of CIP by MWCNTs/AC using a synthetic solution was obtained in $\mathrm{pH}$ of 7, contact time of $30 \mathrm{~min}$, adsorbent dosage of $20 \mathrm{mg} / \mathrm{L}$, temperature of $40{ }^{\circ} \mathrm{C}$, and initial CIP concentration of 
$20 \mathrm{mg} / \mathrm{L}$. Then, the adsorption of CIP under optimal conditions for an actual sewage sample was obtained $73 \%$; however, this value for the synthetic solution was $100 \%$. The reduced removal efficiency in the actual sample can be due to interfering factors including cations, anions, and other contaminants which are present in the sewage sample.

\section{Adsorption mechanism}

Considering that the adsorbent $\mathrm{pH}_{\mathrm{zpc}} 8$ has been obtained, at $\mathrm{pH}$ values above eight levels of adsorbent have a negative bar and at $\mathrm{pH}$ below 8 levels of adsorbent have a positive bar. The optimum $\mathrm{pH}$ of the process is 7 , so at this $\mathrm{pH}$ the adsorbent level will be positively bar. Now, in order to maximize the interaction of electrostatic gravity between adsorbent (positive-load) and contaminate, the pollutant must be negatively bar. The optimum $\mathrm{pH}$ of the process is 7 , and at this $\mathrm{pH}, \mathrm{CIP}$ is in the form of bipolar (neutral), not anionic form. So here the effect of electrostatic gravity does not have much effect, and often the contaminant release solvent effect is affected (Rasoulzadeh et al. 2019) (Fig. 14).

\section{Comparison of the performance of the AC, MWCNTs, MWCNTs/AC adsorbents}

In the present study, the adsorption capacity of MWCNTs/ AC to remove CIP was obtained $150 \mathrm{mg} / \mathrm{g}$ with the removal efficiency of $100 \%$. Our results showed greater adsorption capacity of MWCNTs/AC as well as higher CIP removal efficiency compared with the findings of Li et al. (2015) (the maximum adsorption capacity of CIP onto electrospun carbon nanofibers was found to be $0.68 \mathrm{mmol} / \mathrm{g}$ ), Mao et al. (2016) (the maximum adsorption capacity of CIP by the modified magnetic carbon composite was obtained $90.1 \mathrm{mg} / \mathrm{g}$ ), and Parlayici et al. (the maximum adsorption capacity for $\mathrm{Cr}(\mathrm{VI})$ using AC/f-MWCNTs was found to be $113.29 \mathrm{mg} / \mathrm{g}$ ). Moreover, our results are comparable with the findings of Ademiluyi et al. (2009), who showed the removal efficiency of $62.4 \%$ for organic contaminants by $\mathrm{AC}$ from waste Nigerian Bamboo.

\section{Recovery of the MWCNTs/AC adsorbent}

In the present study, the adsorbent was efficiently recovered by the $\mathrm{NaOH}$ solution. However, Ching et al. used electrochemical processes in order to recover carbon nanotubes and achieved the maximum regeneration efficiency of $69 \%$ (Yuan et al. 2011). Moreover, Bina et al. (2012) showed that the thermal regeneration could enhance the adsorbent performance.

\section{Conclusions}

In the present study, the adsorption of ciprofloxacin (CIP) in the batch system on MWCNTs/AC was investigated. This adsorbent was described following its characterization and identification by different analytical techniques like particle size distribution (PSD), Fourier transform infrared spectroscopy (FTIR), and scanning electron microscopy (SEM). The important parameters affecting the removal efficiency of CIP, such as initial concentration of CIP, adsorbent dosage, $\mathrm{pH}$ of the solution, temperature, and contact time, were investigated. The results of FTIR showed that MWCNTs/ AC functional groups involve in the adsorption of CIP molecules. The results of BET suggested MWCNTs/AC composite to be a mesoporous material. Adsorbent dosage, contact time, and temperature potentially affect the adsorption capacity. The outstanding removal efficiency of $73 \%$ was obtained using MWCNTs/AC in an actual sample. Quantity uptake of CIP was evaluated using the Langmuir, Freundlich, and Temkin models. According to the results, Freundlich isotherm fitted well with the experimental data. Kinetic studies showed that the pseudo-second-order model fitted well with the experimental data. Therefore, it is suggested that MWCNTs/AC composite can effectively be used as a
Fig. 14 Molecular structure of ciprofloxacin and its ionic forms with different $\mathrm{pH}$ values in aqueous solution (Rasoulzadeh et al. 2019)
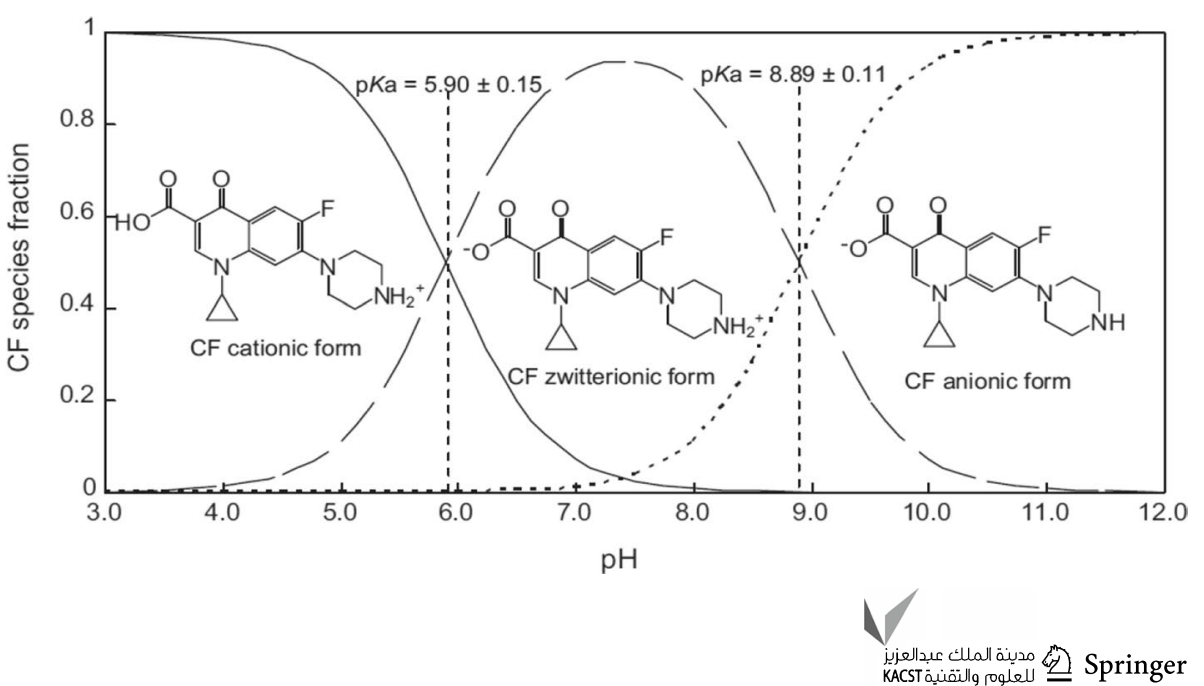
potential tool for environmental applications, especially in antibiotic removal.

Acknowledgements This research emanated from a Master's thesis was conducted at the Environmental Health Engineering Research Center and was sponsored by the Vice-Chancellor for Research and Technology of the Kerman University of Medical Sciences. A note of appreciation is expressed here to the Vice-Chancellor and all the university staff who provided assistance to make this study possible.

\section{Compliance with ethical standards}

Conflict of interest The authors declare that they have no conflict of interest.

Open Access This article is licensed under a Creative Commons Attribution 4.0 International License, which permits use, sharing, adaptation, distribution and reproduction in any medium or format, as long as you give appropriate credit to the original author(s) and the source, provide a link to the Creative Commons licence, and indicate if changes were made. The images or other third party material in this article are included in the article's Creative Commons licence, unless indicated otherwise in a credit line to the material. If material is not included in the article's Creative Commons licence and your intended use is not permitted by statutory regulation or exceeds the permitted use, you will need to obtain permission directly from the copyright holder. To view a copy of this licence, visit http://creativecommons.org/licenses/by/4.0/.

\section{References}

Abdelsalam M, Mokhtar M, Basahel S, Al-Thabaiti S, Obaid A (2010) Removal of chlorophenol from aqueous solutions by multi-walled carbon nanotubes: kinetic and thermodynamic studies. J Alloy Compd 500:87-92

Ademiluyi F, Amadi S, Amakama NJ (2009) Adsorption and treatment of organic contaminants using activated carbon from waste Nigerian Bamboo. J Appl Sci Environ Manag 13(3):39-47

Al-Heetimi DTA, Kadhum MAR, Alkhazrajy OS (2014) Adsorption of ciprofloxacin hydrochloride from aqueous solution by Iraqi porcelinaite adsorbent issue. Al-Nahrain J Sci 17(1):41-49

Alimohammadi M, Saeedi Z, Akbarpour B, Rasoulzadeh H, Yetilmezsoy K, Al-Ghouti MA, Khraisheh M, McKay G (2017) Adsorptive removal of arsenic and mercury from aqueous solutions by eucalyptus leaves. Water Air Soil Pollut 228(11):429

Al-Kaim AF, Baqir SJ, Kadhum AM (2008) Kinetic study for adsorption of para nitroaniline (PNA) on Bentonite clay surface. Iraqi Natl J Chem 32:625-636

Al-Othman ZA, Ali R, Naushad M (2012) Hexavalent chromium removal from aqueous medium by activated carbon prepared from peanut shell: adsorption kinetics, equilibrium and thermodynamic studies. Chem Eng J 184:238-247

Arasteh R, Masoumi M, Rashidi A, Moradi L, Samimi V, Mostafavi S (2010) Adsorption of 2-nitrophenol by multi-wall carbon nanotubes from aqueous solutions. Appl Surf Sci 256(14):4447-4455

Bajpai S, Chand N, Mahendra M (2014) The adsorptive removal of a cationic drug from aqueous solution using poly (methacrylic acid) hydrogels. Water SA 40(1):49-56

Balarak D, Mostafapour FK, Bazrafshan E, Mahvi AH (2017) The equilibrium, kinetic, and thermodynamic parameters of the adsorption of the fluoride ion on to synthetic nano sodalite zeolite. Fluoride 50(2):223-234
Basahel SN, Al Thabaiti SA, Obaid AY, Mokhtar M, Salam MA (2009) Chemical modification of multi-walled carbon nanotubes using different oxidising agents: optimisation and characterisation. Int J Nanopart 2(1):200

Bazrafshan E, Mostafapour FK, Faridi H, Farzadkia M, Sargazi S, Sohrabi A (2013) Removal of 2, 4-dichlorophenoxyacetic acid (2, 4-D) from aqueous environments using single-walled carbon nanotubes. Health Scope 2(1):39-46

Bazrafshan E, Kord Mostafapour F, Rahdar S, Mahvi AH (2015) Equilibrium and thermodynamics studies for decolorization of Reactive Black 5 (RB5) by adsorption onto MWCNTs. Desalination Water Treat 54(8):2241-2251

Bijan B, Alimorad R, Hamidreza P (2012) Using carbon nanotubes to remove benzene and toluene from aqueous solutions. J Health Syst Res 7(6):1203-1215

Dehghani MH, Alimohammadi M, Mahvi AH, Rastkari N, Mostofi M, Gholami M (2014) Performance of multiwall carbon nanotubes for removal phenol from aqueous solutions. Iran J Health Environ 6(4):491-502

El-Shafey E-SI, Al-Lawati H, Al-Sumri AS (2012) Ciprofloxacin adsorption from aqueous solution onto chemically prepared carbon from date palm leaflets. J Environ Sci 24(9):1579-1586

Ghobadi J, Arami M, Bahrami H (2013) Modification of multi walled carbon nanotubes and its application for removal of Direct Blue 86. J Color Scie Technol 2013(7):103-112

Iijima S (1991) Helical microtubules of graphitic carbon. Nature 354(6348):56

Javid N, Nasiri A, Malakootian M (2019) Removal of nonylphenol from aqueous solutions using carbonized date pits modified with ZnO nanoparticles. Desalination Water Treat 141:140-148

Jerold M, Vasantharaj K, Joseph D, Sivasubramanian V (2017) Fabrication of hybrid biosorbent nanoscale zero-valent iron-Sargassum Swartzii biocomposite for the removal of crystal violet from aqueous solution. Int J Phytorem 19(3):214-224

Li K, Zheng Z, Feng J, Zhang J, Luo X, Zhao G, Huang X (2009) Adsorption of $\mathrm{p}$-nitroaniline from aqueous solutions onto activated carbon fiber prepared from cotton stalk. J Hazard Mater 166(2-3):1180-1185

Li K, Li Y, Zheng Z (2010) Kinetics and mechanism studies of p-nitroaniline adsorption on activated carbon fibers prepared from cotton stalk by $\mathrm{NH}_{4} \mathrm{H}_{2} \mathrm{PO}_{4}$ activation and subsequent gasification with steam. J Hazard Mater 178(1-3):553-559

Li X, Chen S, Fan X, Quan X, Tan F, Zhang Y, Gao J (2015) Adsorption of ciprofloxacin, bisphenol and 2-chlorophenol on electrospun carbon nanofibers: in comparison with powder activated carbon. J Colloid Interface Sci 447:120-127

Li Y, Hu X, Liu X, Zhang Y, Zhao Q, Ning P, Tian S (2018) Adsorption behavior of phenol by reversible surfactant-modified montmorillonite: mechanism, thermodynamics, and regeneration. Chem Eng J 334:1214-1221

Liu Y, Liu X, Zhang G, Ma T, Du T, Yang Y, Lu S, Wang W (2019) Adsorptive removal of sulfamethazine and sulfamethoxazole from aqueous solution by hexadecyl trimethyl ammonium bromide modified activated carbon. Colloids Surf A 564:131-141

Loqman A, El Bali B, Lützenkirchen J, Weidler PG, Kherbeche A (2017) Adsorptive removal of crystal violet dye by a local clay and process optimization by response surface methodology. Appl Water Sci 7(7):3649-3660

Luo C, Wei R, Guo D, Zhang S, Yan S (2013) Adsorption behavior of $\mathrm{MnO}_{2}$ functionalized multi-walled carbon nanotubes for the removal of cadmium from aqueous solutions. Chem Eng J 225:406-415

Mahdizadeh H, Malakootian M (2019) Optimization of ciprofloxacin removal from aqueous solutions by a novel semi-fluid Fe/charcoal micro-electrolysis reactor using response surface methodology. Process Saf Environ Prot 123:299-308 
Malakootian M (2017) Performance evaluation of multi-walled carbon nanotubes oxidized with a mixture of $\mathrm{H}_{2} \mathrm{SO}_{4} / \mathrm{HNO}_{3}$ in removal of 4-chlorophenol from aqueous solutions. Sci J Ilam Univ Med Sci 25(1):80-91

Malakootian M, Ehrampoush M, Alibeigi A (2015) The study of oxidized multi-walled carbon nanotubes efficiency in lead removing from aqueous solutions. Toloo-e-Behdasht 14(2):115-124

Malakootian M, Hashemi M, Toolabi A, Nasiri A (2018a) Investigation of nickel removal using poly (amidoamine) generation 4 dendrimer (PAMAM G4) from aqueous solutions. J Eng Res 6(2):13-23

Malakootian M, Mahdizadeh H, Nasiri A, Mirzaienia F, Hajhoseini M, Amirmahani N (2018b) Investigation of the efficiency of microbial desalination cell in removal of arsenic from aqueous solutions. Desalination 438:19-23

Malakootian M, Nasiri A, Mahdizadeh H (2018c) Preparation of CoFe2O4/activated carbon@chitosan as a new magnetic nanobiocomposite for adsorption of ciprofloxacin in aqueous solutions. Water Sci Technol 78(10):2158-2170

Malakootian M, Nasiri A, Amiri Gharaghani M (2019a) Photocatalytic degradation of ciprofloxacin antibiotic by $\mathrm{TiO}_{2}$ nanoparticles immobilized on a glass plate. Chem Eng Commun 20:1-17

Malakootian M, Olama N, Nasiri A (2019b) Photocatalytic degradation of metronidazole from aquatic solution by $\mathrm{TiO}$ 2-doped Fe 3 + nano-photocatalyst. Int J Environ Sci Technol 16(8):4275-4284

Malakootian M, Yaseri M, Faraji M (2019c) Removal of antibiotics from aqueous solutions by nanoparticles: a systematic review and meta-analysis. Environ Sci Pollut Res 26(9):8444-8458

Mao H, Wang S, Lin J-Y, Wang Z, Ren J (2016) Modification of a magnetic carbon composite for ciprofloxacin adsorption. J Environ Sci 49:179-188

Massoudinejad M, Rasoulzadeh H, Ghaderpoori M (2019) Magnetic chitosan nanocomposite: fabrication, properties, and optimization for adsorptive removal of crystal violet from aqueous solutions. Carbohyd Polym 206:844-853

Mifsud M, Vella J, Ferrito V, Serracino-Inglott A, Azzopardi LM, Bartolo NS, LaFerla G, Sammut C (2014) A simple HPLC-UV method for the determination of clindamycin in human plasma. J Chem Pharm Res 6(1):696-704

Moussavi S, Ehrampoush M, Mahvi A, Rahimi S, Ahmadian M (2014) Efficiency of multi-walled carbon nanotubes in adsorbing humic acid from aqueous solutions. Asian J Chem 26(3):821

Naghipour D, Taghavi K, Moslemzadeh M (2016) Removal of methylene blue from aqueous solution by Artist's Bracket fungi: kinetic and equilibrium studies. Water Sci Technol 73(11):2832-2840

Naghizadeh A, Nasseri S, Nazmara S (2011) Removal of trichloroethylene from water by adsorption on to multiwall carbon nanotubes. Iran J Environ Health Sci Eng 8(4):375-382

Nasiri A, Tamaddon F, Mosslemin MH, Gharaghani MA, Asadipour A (2019) New magnetic nanobiocomposite CoFe 2 O 4 @ methycellulose: facile synthesis, characterization, and photocatalytic degradation of metronidazole. J Mater Sci Mater Electron 30(9):8595-8610

Naushad M, Al Othman Z, Khan M (2013) Removal of malathion from aqueous solution using De-Acidite FF-IP resin and determination by UPLC-MS/MS: equilibrium, kinetics and thermodynamics studies. Talanta 115:15-23

Parlayici S, Eskizeybek V, Avcı A, Pehlivan E (2015) Removal of chromium (VI) using activated carbon-supported-functionalized carbon nanotubes. J Nanostruct Chem 5(3):255-263

Peng X, Hu F, Lam FL, Wang Y, Liu Z, Dai H (2015) Adsorption behavior and mechanisms of ciprofloxacin from aqueous solution by ordered mesoporous carbon and bamboo-based carbon. J Colloid Interface Sci 460:349-360

Pourkarim S, Ostovar F, Mahdavianpour M, Moslemzadeh M (2017) Adsorption of chromium (VI) from aqueous solution by Artist's Bracket fungi. Sep Sci Technol 52(10):1733-1741

Rasoulzadeh H, Mohseni-Bandpei A, Hosseini M, Safari M (2019) Mechanistic investigation of ciprofloxacin recovery by magnetiteimprinted chitosan nanocomposite: isotherm, kinetic, thermodynamic and reusability studies. Int J Biol Macromol 133:712-721

Salam MA, Mokhtar M, Basahel SN, Al-Thabaiti S, Obaid AY (2010) Removal of chlorophenol from aqueous solutions by multi-walled carbon nanotubes: kinetic and thermodynamic studies. J Alloys Compd 500(1):87-92

Samadi MT, Shokoohi R, Araghchian M, Azar MT (2014) Amoxicillin removal from aquatic solutions using multi-walled carbon nanotubes. J Mazandaran Univ Med Sci 24(117):103-115

Shah NS, Khan JA, Sayed M, Khan ZUH, Ali HS, Murtaza B, Khan HM, Imran M, Muhammad N (2019) Hydroxyl and sulfate radical mediated degradation of ciprofloxacin using nano zerovalent manganese catalyzed S2O82- ${ }^{-}$Chem Eng J 356:199-209

Upadhyayula VK, Deng S, Mitchell MC, Smith GB (2009) Application of carbon nanotube technology for removal of contaminants in drinking water: a review. Sci Total Environ 408(1):1-13

Wepasnick KA, Smith BA, Schrote KE, Wilson HK, Diegelmann SR, Fairbrother DH (2011) Surface and structural characterization of multi-walled carbon nanotubes following different oxidative treatments. Carbon 49(1):24-36

Worch E (2012) Adsorption technology in water treatment: fundamentals, processes, and modeling. Walter de Gruyter, Berlin

Xiao G, Wen R, Wei D, Wu D (2014) Effects of the steric hindrance of micropores in the hyper-cross-linked polymeric adsorbent on the adsorption of p-nitroaniline in aqueous solution. J Hazard Mater 280:97-103

Xu Y, Liu J, Xie M, Jing L, Xu H, She X, Li H, Xie J (2019) Construction of novel CNT/LaVO ${ }_{4}$ nanostructures for efficient antibiotic photodegradation. Chem Eng J 357:487-497

Yu F, Sun S, Han S, Zheng J, Ma J (2016) Adsorption removal of ciprofloxacin by multi-walled carbon nanotubes with different oxygen contents from aqueous solutions. Chem Eng J 285:588-595

Yuan C, Dai Y-D, Hung C-H (2011) Regeneration of spent carbon nanotube by electrokinetic process with binary metallic oxide electrodes of $\mathrm{MnO}_{2} / \mathrm{Ti} \mathrm{RuO} / \mathrm{Ti}$, and $\mathrm{PbO}_{2} / \mathrm{Ti}$. Sep Purif Technol 79(2):238-245

Publisher's Note Springer Nature remains neutral with regard to jurisdictional claims in published maps and institutional affiliations. 